\title{
A Pyrrhic Victory: The PMN Response to Ocular Bacterial Infections
}

\author{
Erin T. Livingston ${ }^{1}\left(\mathbb{D}\right.$, Md Huzzatul Mursalin ${ }^{1} \mathbb{D}$ and Michelle C. Callegan 1,2,3,4,* \\ 1 Department of Microbiology and Immunology, The University of Oklahoma Health Sciences Center, \\ Oklahoma City, OK 73104, USA; erin-livingston@ouhsc.edu (E.T.L.); \\ MDHuzzatul-Mursalin@ouhsc.edu (M.H.M.) \\ 2 Department of Ophthalmology, The University of Oklahoma Health Sciences Center, Oklahoma City, \\ OK 73104, USA \\ 3 Oklahoma Center for Neuroscience, The University of Oklahoma Health Sciences Center, Oklahoma City, \\ OK 73104, USA \\ 4 Dean McGee Eye Institute, Oklahoma City, OK 73104, USA \\ * Correspondence: michelle-callegan@ouhsc.edu
}

Received: 3 October 2019; Accepted: 5 November 2019; Published: 7 November 2019

check for updates

\begin{abstract}
Some tissues of the eye are susceptible to damage due to their exposure to the outside environment and inability to regenerate. Immune privilege, although beneficial to the eye in terms of homeostasis and protection, can be harmful when breached or when an aberrant response occurs in the face of challenge. In this review, we highlight the role of the PMN (polymorphonuclear leukocyte) in different bacterial ocular infections that invade the immune privileged eye at the anterior and posterior segments: keratitis, conjunctivitis, uveitis, and endophthalmitis. Interestingly, the PMN response from the host seems to be necessary for pathogen clearance in ocular disease, but the inflammatory response can also be detrimental to vision retention. This "Pyrrhic Victory" scenario is explored in each type of ocular infection, with details on PMN recruitment and response at the site of ocular infection. In addition, we emphasize the differences in PMN responses between each ocular disease and its most common corresponding bacterial pathogen. The in vitro and animal models used to identify PMN responses, such as recruitment, phagocytosis, degranulation, and NETosis, are also outlined in each ocular infection. This detailed study of the ocular acute immune response to infection could provide novel therapeutic strategies for blinding diseases, provide more general information on ocular PMN responses, and reveal areas of bacterial ocular infection research that lack PMN response studies.
\end{abstract}

Keywords: polymorphonuclear leukocytes; neutrophils; innate immunity; bacteria; keratitis; conjunctivitis; endophthalmitis; uveitis

\section{Introduction}

In the 1940s, the unresponsive nature of the ocular immune environment was recognized by Sir Peter Medawar, who observed that foreign tissue grafts were not rejected when placed in the anterior chamber (AC) of the eye [1]. Medawar called this special relationship between the eye and the immune system "immune privilege". Nearly eight decades of research on immune privilege has highlighted its highly intricate character, which is the result of highly coordinated interactions between multiple factors and mechanisms. One of these mechanisms is the efficient blood-retina barrier, which prevents the unrestricted entry and exit of cells and large molecules into and out of the eye. The eye also has a deficiency of efferent lymphatics, which also contributes to restricting infiltrating immune cells. Another contributing factor to immune privilege is the inhibitory ocular microenvironment of the 
eye. This unique environment consists of cell-bound and soluble immunosuppressive factors, which inhibits the recruitment and activity of immune cells. Involved in these processes are surface-bound molecules, including CD86, FasL, thrombospondin, and galectins [2,3]. Soluble factors include transforming growth factor-beta (TGF- $\beta$ ), calcitonin gene-related peptide (CGRP, a neuropeptide), and vasoactive intestinal peptide (VIP) [4,5]. Indeed, several mechanisms of immunosuppression and immunoregulation are utilized by the eye to establish and preserve immune privilege.

Other factors such as complement system proteins, antimicrobial peptides, and resident immune cells contribute to destroying pathogens without damaging ocular tissue. For example, tear fluid contains various antibacterial substances (lysozyme, lactoferrin, and surfactant protein D) secreted by lacrimal gland cells and ocular surface epithelial cells [6,7]. Complement in the vitreous is important in host defense against bacterial corneal infections [8], but may not be important in intraocular infections [9]. Soluble factors can be secreted by ocular resident cells, and these cells can also directly inhibit immune cells by contact-dependent mechanisms. For instance, the pigmented epithelia of the retina (RPE) and the iris or ciliary body have been shown to inhibit immune cell infiltration and induce $\mathrm{T}$ cells to become T regulatory cells [2]. However, in the face of severe infection, ocular immunosuppression cannot always effectively keep all immune cells from infiltrating and responding. This may be due to dysfunction of the protective blood-retina barrier caused by the pathogen, resulting in an infiltration of non-resident immune cells. These non-resident cells can cause irreversible tissue damage. Importantly, polymorphonuclear leukocytes (PMNs) have been consistently reported as one of the first responders and the most predominant cell type infiltrating into the eye when infection occurs $[10,11]$.

More than $10^{11}$ PMNs, or neutrophils, are produced every day in the bone marrow, and these cells represent approximately $70 \%$ of all leukocytes [12]. With this impressive amount of production, it is no surprise that PMNs are also the most abundant white blood cell type in the human blood. Once in the blood, PMNs are trafficked to sites of infection. This process is known as the leukocyte adhesion cascade [13]. During this process, endothelial cells are activated by inflammatory chemokines or other chemoattractant factors released by cells affected during inflammation. When activated, endothelial cells express adhesion molecules on the luminal surface, such as intracellular adhesion molecule 1 (ICAM1) and vascular cell adhesion molecule 1 (VCAM1), causing PMN arrest and transmigration through the endothelial layer. PMNs display a different phenotype from the time they enter circulation to the time they migrate across the endothelial layer to a site of infection. This shift in phenotype is caused by transcriptional activation that is mediated, in part, by local granulocyte colony-stimulating factor (G-CSF) production and by changes in surface molecule expression or activity regulated by inflammatory factors at the infection site [14].

When PMNs recognize a pathogen, these cells utilize different functions and responses to clear the infection [14-16]. Phagocytosis involves the consumption of the organism into a phagocytic vacuole. This vacuole becomes a phagolysosome in which the organism is destroyed by low $\mathrm{pH}$ and destructive enzymes. PMNs also degranulate, releasing granules that contain a plethora of antimicrobial enzymes, into the extracellular environment. However, when the organism is too large to be consumed, PMNs can ensnare the pathogen by producing neutrophil extracellular traps (NETs). NETs are a tangle of DNA fibers and proteins released from PMN granules. In addition, PMNs can acquire specialized functions depending on their microenvironment $[16,17]$. PMNs, which are recruited into different areas of the infected eye (Figure 1), use a combination of these functions to fight a variety of bacterial ocular infections. Very similar to a "Pyrrhic Victory" scenario, PMN responses are necessary for clearing pathogens in the eye, but, as this review will highlight, the process of these responses has the unfortunate side effect of damaging and scarring delicate ocular tissues and threatening sight. 


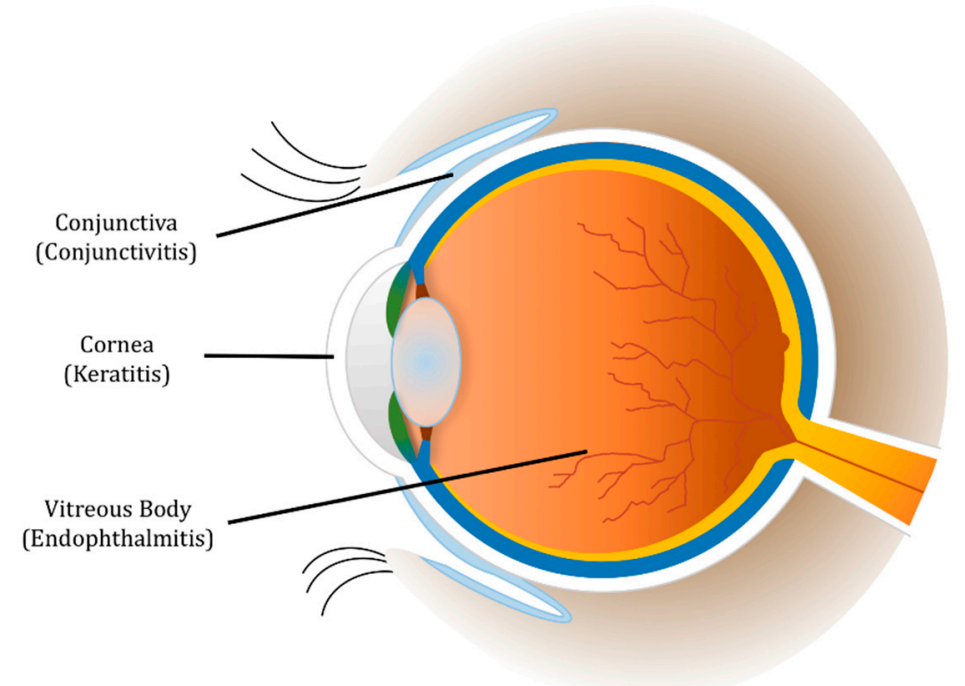

Figure 1. Diagram of the eye and sites of ocular inflammation. This figure illustrates areas of ocular infection and inflammation, such as conjunctivitis, keratitis, and endophthalmitis. The polymorphonuclear leukocyte (PMN) responses to the diseases shown in the diagram will be discussed. Note: Inflammation of the eye is also called uveitis, which will be discussed in its own section.

\section{Conjunctivitis}

Conjunctivitis results from inflammation of the conjunctiva, which is the transparent, lubricating mucous membrane that covers the anterior of the eye. The cause of this inflammation can be due to infectious or non-infectious agents. Conjunctivitis can also result from an aberrant proliferation of the conjunctival flora [18]. The result of an infection of this tissue is injection or dilation of the conjunctival vessels. Thus, the classic discharge, redness or hyperemia, and edema of the conjunctiva occurs (Figure 2). This infection can affect people of any age and demographic, but the disease is easily treatable and usually self-limiting. While these infections can be painful, they are typically responsive to topical antibiotics [19]. Most bacterial conjunctivitis patients receiving proper treatment recover with little to no change in visual acuity [20-22].

Bacterial conjunctivitis can spread by direct contact and has high transmission rates. The incidence of bacterial conjunctivitis is estimated to be 135 in 10,000 [21]. Transmission routes include the spread of fomites via contaminated fingers or oculogenital spread [22,23]. Predisposing factors for bacterial conjunctivitis include aberrant tear production, epithelial barrier disruption or dysfunction, trauma, and immunosuppression [24]. A large infiltration of inflammatory cells occurs during this infection. An infiltration of PMNs suggests a bacterial infection, while an infiltration of lymphocytes indicates viral and allergic conjunctivitis [25]. In adults, the most common bacterial pathogens for conjunctivitis are Chlamydia trachomatis, staphylococci, and Streptococcus pneumoniae [18,22-24,26]. 

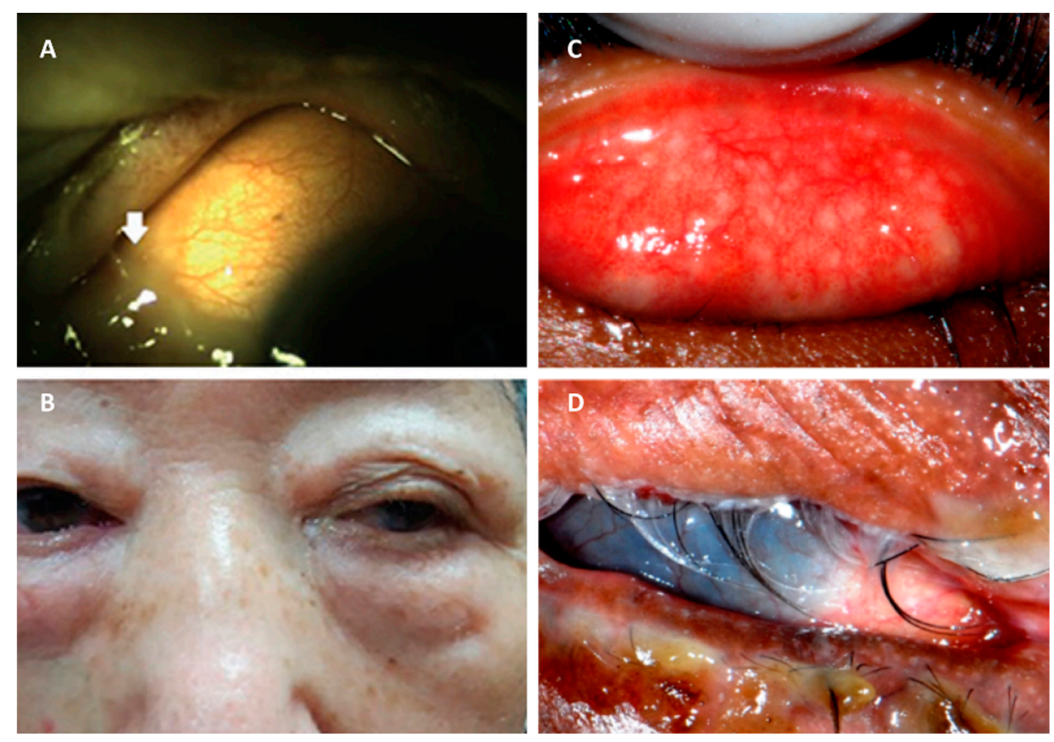

Figure 2. Trachoma and methicillin-resistant Staphylococcus aureus (MRSA) conjunctivitis. (A) and (B) A patient with MRSA conjunctivitis shows thick mucoid discharge at the conjunctival sac (arrow) of the left eye. (C) and (D) A patient with trachoma with trachomatous inflammation and follicular and/or trachomatous trichiasis (inversion of eyelashes). This figure is a combination of two edited figures reproduced under a Creative Commons License from (C2016 Korean Journal of Ophthalmology [27] and (C) 2013 PLoS Neglected Tropical Diseases [28].

\subsection{Staphylococcus aureus Conjunctivitis}

Staphylococcus aureus causes many infections including brain abscesses, osteomyelitis, pneumonia, septicemia, and skin infections [22,29,30]. This important human pathogen is a Gram-positive coccus, and is a leading cause of many ocular infections as well, including conjunctivitis, endophthalmitis, and keratitis [29-33]. To treat $S$. aureus conjunctivitis, empiric broad-spectrum antibiotic therapy typically shortens the recovery time and lessens the symptoms. However, Hautala et al. [34] reported that this infection is becoming more difficult to treat with the discovery that $S$. aureus isolates are increasingly methicillin-resistant (MRSA).

The infiltration and presence of PMNs during S. aureus conjunctivitis has been well described [25, 35-37]. McCormick et al. [35] showed that the amount of infiltration and localization of PMN in the rabbit conjunctiva was dependent on the virulence of the infecting $S$. aureus strain being used. This model is particularly difficult to replicate due to the ability of the conjunctiva to rapidly recover with no apparent tissue damage. In this model, well-characterized laboratory strains grew slowly, resulting in a more localized PMN presence in the conjunctiva. In contrast, an ocular isolate obtained from a rabbit replicated much faster, resulting in a more significant PMN infiltration into the conjunctiva [35]. Zaidi et al. [37] reported that PMN infiltration may be dependent on the expression of surface/capsular polysaccharide poly-N-acetyl glucosamine (PNAG) on S. aureus and Streptococcus pneumoniae. Blocking PNAG with an opsonic antibody reduced the number of PMN infiltrating into the conjunctiva [37]. These studies demonstrated how certain staphylococcal factors affected the infiltration and localization of PMN in conjunctivitis. However, it is clear that studies on the role of the PMN and their function in S. aureus conjunctivitis are lacking. Studies on PMN function during S. aureus conjunctivitis will provide a clearer understanding of pathology for this disease.

\subsection{Streptococcus pneumoniae Conjunctivitis}

S. pneumoniae is a common cause of ocular surface infections $[22,38,39]$. This disease is associated with occurrences involving people in close living quarters, including university and military dormitories, daycare facilities, and special care facilities [38-41]. S. pneumoniae is one of the most common 
causative agents of acute conjunctivitis in children [42]. A majority of these outbreaks are caused by non-encapsulated strains $[38,43]$. The capsule of S. pneumoniae allows the bacteria to evade phagocytosis and killing, and the capsule is a known virulence factor in pneumonia and bacteremia [44-46]. Inflammation and the presence of PMNs during experimental S. pneumoniae conjunctivitis have been observed [47]. However, just as with $S$. aureus conjunctivitis studies, the study of the specific roles of PMNs during this infection is lacking.

Perhaps the most in-depth study thus far is from Norcross et al. [47], who observed slightly less infiltrating PMNs and macrophages in the rabbit conjunctiva infected with a non-encapsulated $S$. pneumoniae strain than eyes infected with an encapsulated strain. Specifically, rabbit conjunctivae infected with the encapsulated strain had more infiltrating PMNs and macrophages in the bulbar and palpebral conjunctivae compared to those infected with the non-encapsulated strain. Numbers of macrophages and granulocytes peaked at $24 \mathrm{~h}$ postinfection in the palpebral conjunctivae and at 48 $\mathrm{h}$ postinfection in bulbar conjunctivae for both strains. The authors speculated that this may be due to the infiltration of circulating PMNs first into the palpebral conjunctivae and then into the bulbar conjunctivae. Overall, the capsule did not seem to contribute to the conjunctivitis severity [47].

Another S. pneumoniae virulence factor is the cholesterol-dependent cytolysin, pneumolysin (PLY). To date, there have been no studies regarding the effects of PLY in S. pneumoniae conjunctivitis. Johnson et al. [48] first described PLY as a membrane-damaging, pore-forming toxin that stimulates proinflammatory interactions with human PMNs. In this study, human PMNs exposed to the PLY showed inhibited chemotaxis, increased cell death, and lysis [48]. Later studies reported that PLY was able to cause an influx of $\mathrm{Ca}^{2+}$ and increased phospholipase A2 activity and CR3 expression in human PMNs, which were associated with enhanced superoxide production and the release of elastase [49]. Whether PLY is involved in altering PMN activity during pneumococcal conjunctival infection is an open question.

Valentino et al. [50] conducted a comparative genomic investigation of 271 conjunctivitis-causing pneumococcal strains from the United States and reported that most of the conjunctivitis strains were closely related unencapsulated strains. These strains have differing cohorts of pneumococcal virulence factors and the inability to metabolize fucose, which is a sugar present in corneal epithelial cells. Fucose residues are associated in the adhesion of E. coli and P. aeruginosa to ocular epithelial cells [51]. Incubation with exogenous fucose was reported to suppress inflammation in rabbit corneas and human explanted models of corneal wound healing [52]. The study by Valentino et al. [50] further suggested that these strains may have a growth advantage by conserving ocular fucose and helping sustain an anti-inflammatory environment. Again, whether PMN are affected in this environment is an open question.

\subsection{Chlamydia trachomatis Conjunctivitis}

C. trachomatis is an obligate intracellular bacterium that causes trachoma, the world's leading cause of preventable blindness [53]. This pathogen can infect the conjunctiva, causing three different syndromes: adult and neonatal inclusion conjunctivitis, lymphogranuloma venereum, and trachoma. C. trachomatis is the most common agent isolated from cases of chronic follicular conjunctivitis, and is responsible for approximately $20 \%$ of acute conjunctivitis cases [54]. Several studies have shown that PMNs are part of the host's response to eradicate this pathogen, but this response also causes host tissue damage $[26,55,56]$.

Rank et al. [56] used transmission electron microscopy in a model of ocular chlamydial infection in guinea pigs to show PMNs in close proximity with infected mucosal epithelial cells. Importantly, the authors demonstrated that PMNs disturbed epithelial focal adhesions. This suggested that PMNs might cause the release of epithelial cells from the conjunctival mucosal epithelium, effectively damaging the host tissue (Figure 3). Lacy et al. [26] showed that PMNs contribute to host conjunctival tissue damage during chlamydial conjunctivitis in PMN-depleted guinea pigs. PMN depletion decreased pathology, but did not eliminate the damage, suggesting that other cells or factors contributing to this pathology. 
While PMNs may not be essential for direct chlamydial clearance in this conjunctivitis model, PMNs might help modulate the adaptive response by downregulating humoral immunity and promoting T-cell recruitment [26].
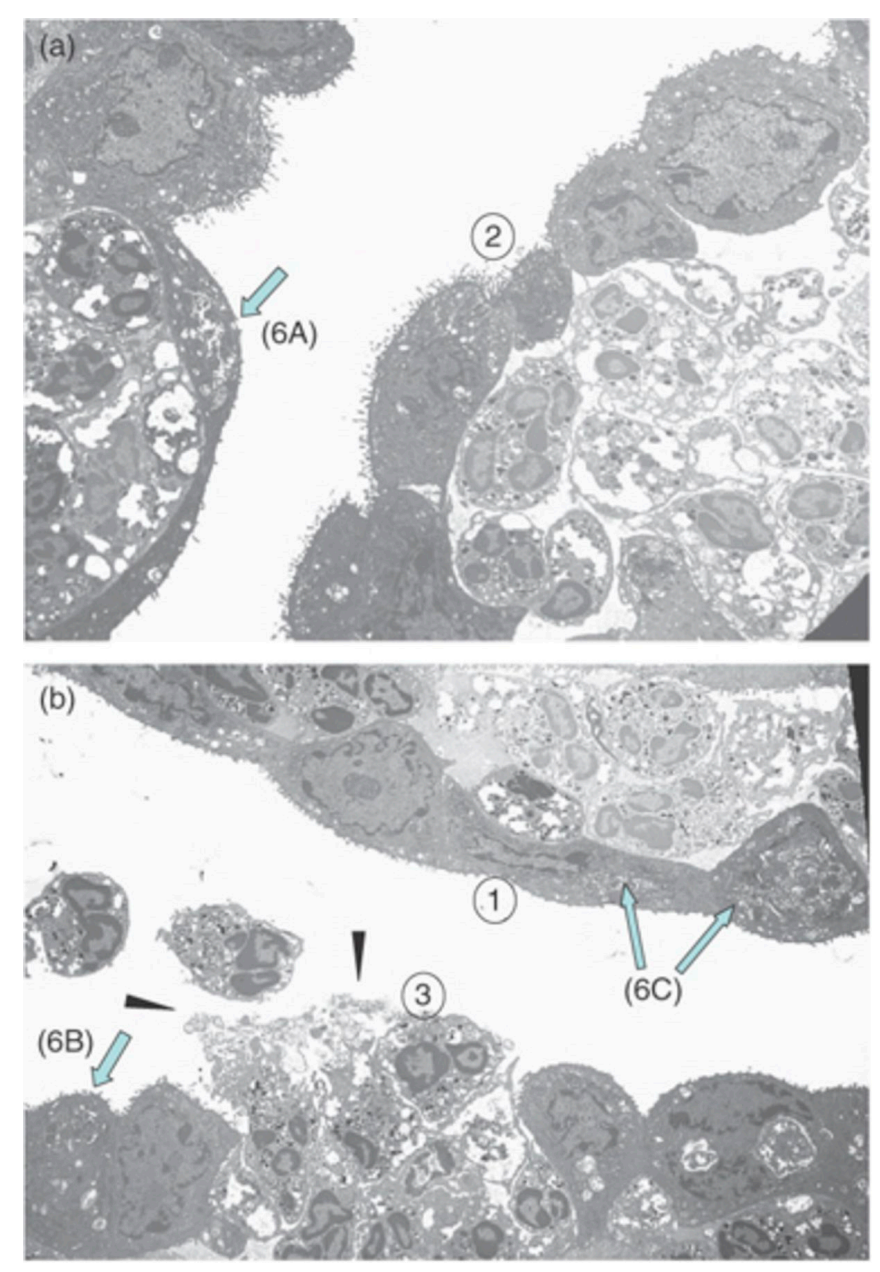

Figure 3. Stages of the PMN response to conjunctival epithelial cells infected by chlamydiae. (A-B) (1) PMNs accumulating immediately behind a barrier of infected epithelial cells (arrows). (2) The epithelium loses integrity. (3) PMNs break through the barrier and are released onto the surface, resulting in the release of damaged epithelial cells (arrowheads). The figure is reproduced from Rank et al. [56] with the permission of Oxford University Press.

Lacy et al. [26] showed that PMNs may downregulate IgA humoral responses in chlamydial infection of the eye. The authors suggested that PMN contributes to the downregulation of TGF- $\beta$ and IL-5, since these mediators were increased when PMNs are depleted. TGF- $\beta$ and IL-5 were both required for the production of IgA. How PMNs downregulate these two cytokines is uncertain. However, TGF- $\beta$ may play an important role because of its multiple functions during an immune response, including the downregulation of inflammation and promotion of IgA production [57]. The evidence presented in this study suggested a greater intricacy in the PMN response to chlamydial infection in the eye than previously suggested. Significantly, this study was the first to propose that PMNs may shape antichlamydial adaptive responses, but may not be important in directly killing chlamydiae at the same time as host tissue damage is occurring [26].

\subsection{Conjunctivitis Conclusions}

Although most cases of conjunctivitis are benign with a self-limited process, this infection can be severe and threaten sight. The standard therapy for conjunctivitis continues to be antibiotics, 
regardless of the causative agent. Topical antibiotics, such as ciprofloxacin, have been shown to reduce the time of infection, decrease transmissibility, and accelerate recovery [22,58]. Topical corticosteroids are not suggested for bacterial conjunctivitis, although the inflammation can cause discomfort [59]. The conjunctivitis studies discussed above demonstrate that one of the major contributors of this inflammation is the influx of PMNs. The amount of PMN influx has been shown to be dependent on the virulence of the pathogen, and in the case of $S$. aureus infections, dependent on the expression of a polysaccharide capsule. The presence of a capsule on S. pneumoniae does not seem to matter in conjunctivitis infections. It is clear that future studies should focus on factors that contribute to PMN responses in S. pneumoniae conjunctivitis. C. trachomatis conjunctivitis models have revealed that PMNs are partly responsible for epithelial damage and the downregulation of humoral immune responses, which drives an adaptive immune response to clear the infection. Studies on mechanisms to reduce humoral responses and increase adaptive responses in this disease may be helpful. Overall, these bacterial conjunctivitis studies reveal a trend that will be seen throughout this review: PMN recruitment into the eye is mainly dependent on the expression of bacterial virulence factors, and the PMN response is damaging to the host cells of the eye.

\section{Keratitis}

Keratitis is a potentially sight-threatening ocular disease, which may result from injuries and epithelial defects of the cornea. The exposure of damaged corneal epithelium to pathogenic bacteria can lead to inflammation of the layers of the cornea, or keratitis. A healthy and intact ocular surface prevents most pathogens from causing infection, but once corneal epithelial barriers are breached and infected, host defenses act to clear infection. PMNs comprise a significant portion of this initial host immune response, and have been shown to have a major role in influencing the outcome of infection [60]. This host immune response, along with pathogens invading the corneal stroma, can lead to a loss of vision due to corneal scarring [60-63]. Predisposing factors of susceptibility to keratitis include the misuse of contact lenses and their sterilizing solutions, ocular surgery or other trauma, chronic ocular surface disease, or systemic diseases such as diabetes mellitus [60,64]. Patients with infectious keratitis commonly present with tearing, redness, pain, and blurred vision. However, the clinical presentation, and subsequently the PMN response, largely varies regarding the bacteria responsible for inducing the infection.

In temperate climates, approximately $90 \%$ of keratitis cases are caused by bacteria. However, microbial keratitis accounts for $60 \%$ of cases in subtropical climates, and fungal keratitis accounts for $35 \%$ of cases in tropical climates [65]. Bacterial keratitis is most often associated with contact lens use in the U.S. These severe infections can cause permanent vision loss, which requires corneal transplantation [66]. The most common organisms that cause bacterial keratitis include Pseudomonas aeruginosa, Staphylococcus aureus, and Streptococcus pneumoniae (Figure 4) [60]. Some bacteria initiate infection by contacting the host cell-surface receptors using adhesins. Adhesins, such as pili or fimbriae, facilitate binding to corneal epithelial cells, and may act as toxins, disrupting barriers, initiating microbial invasion, and activating inflammatory cascades $[67,68]$. The adherence to the damaged corneal epithelium of P. aeruginosa, S. pneumoniae, and S. aureus is significantly greater compared to that of other bacteria, which may explain their frequency in isolation from keratitis cases $[69,70]$. Once invasion has ensued, corneal tissue can be quickly damaged due to the activities of bacterial toxins and proteolytic enzymes, the activation of corneal metalloproteases, and stimulation of the immune response [62,71]. Responding PMNs also contribute to corneal damage by releasing reactive oxygen species (ROS) and host proteases. These responses are also important for clearing the infection, but some bacteria are able to avoid PMN killing by modulating the antimicrobial functions of PMN in the cornea [72]. 

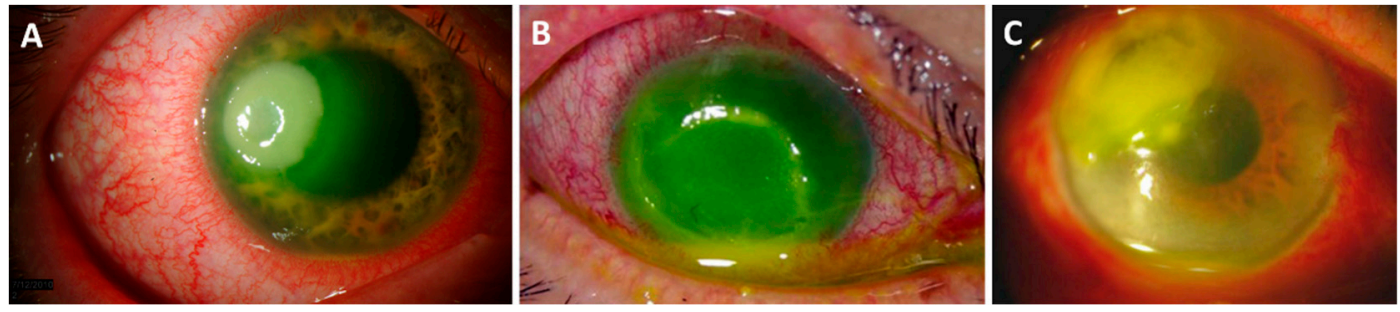

Figure 4. P. aeruginosa, MRSA, and S. pneumoniae keratitis. (A) A corneal ulcer caused by P. aeruginosa. PMN fill the ulcer, which may perforate the cornea. (B) A patient with MRSA keratitis after penetrating keratoplasty. This patient was treated with topical antibiotics and corticosteroids. (C) S. pneumoniae keratitis in a patient showing corneal abscess and thinning. Part A is an edited figure reproduced under a Creative Commons Attribution-NonCommercial-NoDerivs 3.0 Unported License from (C) 2012 EyeRounds Online Atlas of Ophthalmology [73]. Parts B and C are reproduced under a Creative Commons Attribution 3.0 License from (C) 2010 Korean Journal of Ophthalmology [74] and (C) 2009 Archives of Medicine [75].

\subsection{Pseudomonas aeruginosa Keratitis}

Early research in the 1970s showed that PMNs are the predominant cell type composing the exudate caused by P. aeruginosa cornea infection [63,76]. Chusid et al. [77] examined the role of PMN in innate immune resistance to $P$. aeruginosa keratitis in neutropenic guinea pigs and found that fewer PMNs infiltrating into the cornea lead to a larger bacterial burden in the eye and less corneal edema. The PMN response to this infection may have also been important for preventing lethal sepsis, as shown in a study using P. aeruginosa-infected and cyclophosphamide-treated mice [78]. Interestingly, PMNs were critical for preventing the spread of $P$. aeruginosa to the brain, possibly via the optic nerve. This observation was also observed in corneal infections in Myeloid Differentiation primary response 88 (MyD88)-deficient mice, in which PMN recruitment is defective. MyD88 is a key signal transduction molecule that mediates the activation of cells after Toll-like receptor (TLR) and/or IL-1 and TNF receptor stimulation [79]. MyD88-deficient mice had functional PMNs in the blood, but these infected mice had observable amounts of $P$. aeruginosa in the brain after the induction of keratitis, suggesting a non-vascular route for bacteria to the brain. A similar observation was made more recently, with the discovery that PMN NETs are important in preventing the spread of P. aeruginosa to the brain after corneal infection. Thanabalasuriar et al. [80] reported that dissemination to the brain was prevented by a PMN NET barrier generated in response to the P. aeruginosa expression of the type- 3 secretion system (T3SS) in a biofilm. Indeed, the T3SS in the Gram-negative P. aeruginosa seems to be important for modulating PMN behavior during corneal infection. Effector proteins secreted by T3SS, such as ExoS and ExoT (Exoenzyme $S$ and T), are responsible in promoting PMN apoptosis in P. aeruginosa keratitis [81] and inhibiting reactive oxygen species production in neutrophils [72].

The flagellum of $P$. aeruginosa also activates innate immune responses in corneal epithelium through interaction with TLRs, which initiate innate immune cascades leading to the production of proinflammatory cytokines in the cornea. In a study conducted on immortalized human corneal epithelial cells (HCECs), Zhang et al. [82] observed that P. aeruginosa flagellum could signal the NF- $\mathrm{kB}$ system through TLR 5 by inducing phosphorylation and the degradation of I $k \mathrm{~B}-\alpha$ (a regulatory protein that inhibits NF- $\mathrm{kB}$ ). This led to the expression and secretion of proinflammatory cytokines IL-6 and IL-8, which are both important in regulating PMN infiltration. In addition to IL-6 and IL-8, the chemokine IL- $1 \beta$ is also a critical mediator of the innate host response to P. aeruginosa keratitis. By using IL-1 $\beta$-deficient mice, Karmakar et al. [83] demonstrated that IL-1 $\beta$ was essential for PMN recruitment and bacterial clearance in P. aeruginosa keratitis. PMNs were the primary source of IL- $1 \beta$ in vivo during this infection, and IL-1 $\beta$ cleavage during infection was dependent on neutrophil elastase, which is a serine protease. This cleavage led to a greater infiltration of PMNs, which was beneficial for bacterial clearance and the prevention of dissemination, but detrimental to the clarity of the corneal epithelium. 
Other chemokines also play an important role in P. aeruginosa keratitis. Xue et al. [84] showed that the CCL2 and CCL3 were critical in recruiting PMNs to the cornea. Treating mice with anti-CCL2 or anti-CCL3 antibodies caused less corneal damage severity and PMN infiltration compared to control antibody-treated eyes. However, antibody treatment did not change the rate of bacterial clearance from the cornea. These results support the contention that CCL2 and CCL3 are important regulators of PMN recruitment, which may lead to therapies that target CCL2 and CCL3 in the treatment of $P$. aeruginosa or possibly other forms of bacterial keratitis.

\subsection{Staphylococcus aureus Keratitis}

A complex PMN response is shared amongst many microbial ocular infections, especially with S. aureus keratitis, which is the most common cause of bacterial keratitis worldwide $[30,60,64,85]$. Unfortunately, an increased incidence of corneal infections by MRSA has also emerged [86,87]. When $S$. aureus infects the corneal stroma and epithelium, it quickly replicates and produces toxins such as hemolytic $\alpha$-toxin [88]. This results in tissue damage, epithelial ulceration, and possibly corneal opacity. S. aureus keratitis also results in PMN infiltration to the corneal stroma. The PMN response of degranulation and the release of cytotoxic mediators possibly contributes to the pathogenesis of this disease [88-92].

Corneal epithelial cells recognize Gram-positive bacteria via the activation of TLRs. This leads to the influx of PMNs to the site of S. aureus keratitis, which has been linked to the activation of TLR2 by the bacteria. Human corneal epithelial cells (HCECs) express TLR2 and, in vitro, respond to viable $S$. aureus, its secreted proteins, and peptidoglycan, but not lipoteichoic acid, by triggering the activation of mitogen-activated protein kinase (MAPK) and NF- $\kappa B$ signaling pathways. Importantly, HCECs also expressed and secreted proinflammatory cytokines, such as IL-6, IL-8, and TNF- $\alpha$. These mediators can recruit inflammatory PMNs to the site of infection [93]. These in vitro observations were supported by a study using TLR2-deficient and MyD88-deficient mice in which TLR2/MyD88 functioned as a detector of S. aureus in the cornea and mediated infiltration of PMNs [94]. The chemokine receptor 2 (CXCR2) has also been implicated as a facilitator of the inflammatory response during S. aureus keratitis. Cole et al. [95] observed that an absence of CXCR2 in mice led to reduced PMN infiltration and higher bacterial replication in eyes compared to that in wild-type (WT) mice, even when chemokines were more highly produced. CXCR2-deficient mice had higher expression levels of ICAM-1 in corneas compared to those in WT mice. Thus, the authors suggested that CXCR2-mediated signaling via the upregulation of adhesion molecules was vital to vascular PMN margination in this model. Khan et al. [96] also reported similar results in a mouse P. aeruginosa keratitis model. The authors concluded that the infiltration of PMNs into the corneal epithelium during P. aeruginosa and S. aureus keratitis was highly dependent on IL-8 activating CXCR2, which therefore upregulated adhesion molecules that are needed for PMN infiltration.

Surfactant protein D (SP-D) is important in host defense and innate immunity, and its role has been studied in P. aeruginosa $[97,98]$ and S. aureus keratitis. This surfactant-associated protein is an innate immune molecule that is capable of binding to lipids and carbohydrates on the surfaces of microorganisms. Importantly, SP-D also binds to receptors on the surface of phagocytic and inflammatory cells, and acts as an opsonin to increase the rate of microbial clearance. In a mouse model of S. aureus infection, Zhang et al. [99] injected the eyes of WT and SP-D-deficient mice with S. aureus and in the presence or absence of a cysteine protease inhibitor (E64), which reduced the degradation of SP-D by the S. aureus cysteine proteases. Bacterial phagocytosis by PMNs was increased in WT mice compared to that of SP-D deficient mice (Figure 5), and WT mice had reduced ocular injury compared with that of SP-D deficient mice. When cysteine inhibitor was present, the WT mice had greater bacterial clearance and reduced ocular injury compared to that of SP-D-deficient mice [99]. Thus, this data suggested that although SP-D protected the ocular surface from S. aureus infection, S. aureus cysteine proteases impaired SP-D function. The authors suggested that for S. aureus keratitis, a cysteine protease inhibitor may be a potential therapeutic agent. 
A

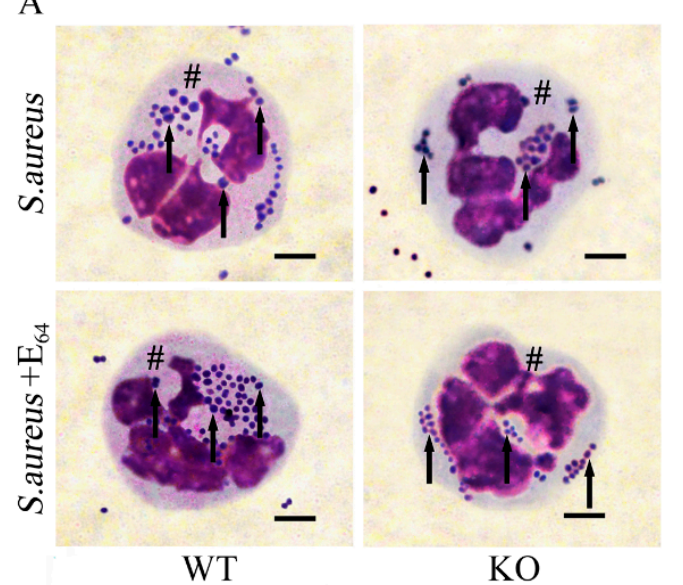

B

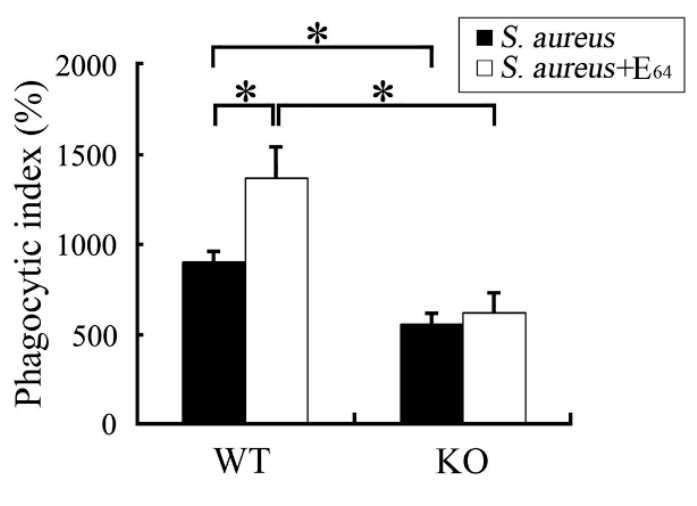

Figure 5. PMN phagocytosis of S. aureus is promoted by surfactant protein D (SP-D), and S. aureus cysteine protease diminished SP-D activity. (A) PMNs shown are from tear fluid after inoculation with S. aureus or S. aureus with E64 (cysteine protease inhibitor). (B) Phagocytic index (PI) from PMNs in the tear fluid of infected wild-type (WT) and SP-D KO mice. \#, PMNs; Arrows, S. aureus. This figure is reproduced under a Creative Commons License from (C) 2015 PLoS ONE [99].

Once PMNs arrive to the site of $S$. aureus corneal infection, these cells are susceptible to the activities of toxins produced by the organism. Approximately $95 \%$ of ocular S. aureus isolates carry the hla/hly gene and have been reported to produce $\alpha$-toxin $[100,101]$. $\alpha$-Toxin subunits bind to and enter the cellular cytoplasmic membrane and oligomerize into a circular pore, facilitating cellular dysregulation. $\alpha$-Toxin binding also leads to the cleavage of E-cadherin molecules, altering barrier function $[102,103]$. Whether this activity extends to the cornea in keratitis is an open question. $\alpha$-Toxin's implications on PMN activity during S. aureus keratitis have been studied to some degree. Callegan et al. [88] reported that rabbit corneas infected with $S$. aureus lacking $\alpha$-toxin did not have as many infiltrating PMNs compared to rabbit corneas infected with WT S. aureus. S. aureus also produces $\beta$-toxin, a sphingomyelinase, which was reported to have a minimal contribution to the inflammation observed in a rabbit keratitis model [91]. Gamma-toxin, another pore-forming toxin produced by $S$. aureus, has been reported to contribute to keratitis inflammation and virulence, but not to the extent as that of $\alpha$-toxin [104].

The role of $S$. aureus protein A, an immunoglobulin-binding cell wall-associated exoprotein, as a virulence factor in S. aureus in corneal infection, has also been analyzed. In vivo, the absence of protein A did not affect inflammation in rabbit corneal infections [88]. An in vitro analysis of HCECs indicated that purified protein A induced an inflammatory response via the secretion of chemokines and proinflammatory cytokines via a mechanism separate from that of the activation of TLRs [105].

\subsection{Streptococcus pneumoniae Keratitis}

Streptococcus pneumoniae has been reported as the third-leading cause of bacterial keratitis, after P. aeruginosa and/or S. aureus $[64,106,107]$. In one study, keratitis caused by S. pneumoniae accounted for $33.3 \%$ of all bacterial keratitis cases [108]. Treating this infection has become increasingly more challenging because of increasing S. pneumoniae resistance to antibiotics [108-110]. Keratitis caused by S. pneumoniae is not usually associated with the use of contact lenses, as are S. aureus and P. aeruginosa. Instead, the predisposing factors of S. pneumoniae keratitis include ocular trauma or surgery [111-114]. The corneal damage observed in pneumococcal keratitis has been credited mainly to pneumococcal virulence factors, such as the toxin pneumolysin (PLY), which damage cells and initiate a robust immune response [11,71,115-119].

The role of PLY in keratitis was first analyzed in rabbit models. Rabbits intrastromally infected with PLY-defective strains of S. pneumoniae had reduced corneal virulence compared to rabbits infected 
with WT strains $[115,117,119]$. Norcross et al. [117] reported similar results with primary rabbit corneal epithelial (RCE) cells in an in vitro model of pneumococcal keratitis. PLY seems to play a role in disease severity by triggering an inflammatory response during corneal infection. During pneumococcal keratitis, fewer PMNs infiltrated to the site of infection in rabbit eyes infected with a PLY-deficient strain compared to that of WT-infected eyes [117]. Leukopenia in rabbits resulted in a decreased severity of damage to the cornea following challenge with purified PLY [116]. This suggested that PMNs are an important instigator of corneal damage during infection. A more recent study investigated the mechanisms by which PMNs process IL-1 $\beta$ in response to $S$. pneumoniae keratitis. In a mouse model, Karmaker et al. [120] reported that PMNs were the predominant source of IL-1 $\beta$ production, which was dependent on PLY triggering the NLRP3/ASC inflammasome and caspase-1. Therefore, these studies indicated that PLY was at least partly responsible for activating the inflammatory response and causing immune-mediated damage.

Another well-studied virulence factor of S. pneumoniae in keratitis is its polysaccharide capsule. The capsule allows bacteria to avoid the host immune system by prohibiting contact between complement components and their receptors on phagocytic cells, preventing killing [121]. Most pneumococcal keratitis cases are reportedly caused by encapsulated bacteria, but specific capsular serotypes are seldom reported [122-124]. Reed et al. [125] reported that the capsule was not an important virulence factor in S. pneumoniae keratitis in the rabbit, but was essential for virulence in intraperitoneal infections in the mouse. When rabbit corneas were infected with a non-encapsulated S. pneumoniae, bacterial growth was less after $48 \mathrm{~h}$ postinfection compared to WT infections. The authors speculated that this was due to the PMNs' ability to more efficiently reduce the numbers of $S$. pneumoniae lacking a capsule [125]. Norcross et al. [47] conducted a similar study in rabbit corneas using a human S. pneumoniae keratitis isolate. In this model, the progression of keratitis was unaffected by the absence of the capsule, but the absence of the capsule facilitated faster pneumococcal clearance. Thus, the pneumococcal capsule's importance in evading phagocytic death in other infections is also important in keratitis.

\subsection{Keratitis Conclusions}

Corneal transparency is important for vision. Bacterial keratitis threatens the clarity of this tissue and ultimately sight when not sufficiently treated at early stages. If antimicrobial treatment is delayed, about $50 \%$ of eyes with keratitis gain useful vision [126]. Typical treatments include the use of a combination of topical antibiotics such as cefazolin, tobramycin, and/or gentamicin. Fourth-generation fluoroquinolones, such as gatifloxacin and moxifloxacin, are also good alternatives [127]. However, killing the bacteria with these antibiotics does not completely clear inflammation. The secreted virulence factors and capsule components are still present after bacteria are killed. Therefore, the inflammatory response to these components might still contribute to PMN recruitment. PMNs contribute to host tissue damage in the cornea, which can lead to corneal scarring. However, PMN depletion only results in greater bacterial growth in the cornea, which typically has devastating consequences. Thus, the conundrum of protective and detrimental PMN responses to bacterial infection in the cornea remains.

\section{Infectious Uveitis Models}

Uveitis defines a collection of conditions characterized by intraocular inflammation. Uveitis technically describes the inflammation of the whole eye, but this section will cover models specifically used to study ocular inflammation in which endotoxin is used to mount an immune response. Infectious uveitis is one of the most frequent and devastating causes of blindness worldwide [128-130].

Bacterial uveitis caused by Treponema pallidum, Borrelia burgdorferi, and Mycobacterium tuberculosis results in significant intraocular inflammation. The spirochete, T. pallidum, causes syphilis. High-risk behavior in HIV and syphilis patients undergoing therapy has added to the increasing occurrence of this disease. Uveitis is the most common ocular manifestation of syphilis, which occurs in approximately $5 \%$ of patients with tertiary syphilis [131]. This infection in the eye can occur at any stage of acquired 
syphilis. B. burgdorferi causes Lyme disease, which occurs when this spirochete is transferred during the bite of an Ixodes tick. Although rare, ocular manifestations of Lyme disease include uveitis and have been reported during all stages of the disease $[132,133]$. Tuberculosis uveitis is most commonly caused by $M$. tuberculosis, with this species isolated in $5.6-10.1 \%$ of uveitis cases in India where pulmonary tuberculosis is endemic $[134,135]$. Unfortunately, infectious uveitis can result in visual loss if the disease is unrecognized or treated incorrectly as non-infectious ocular inflammation. The inflammatory process is divided into acute and chronic inflammation. During acute inflammation, the primary infiltrating cells are PMNs and macrophages. Edema and vascular dilation and congestion also occur. In chronic inflammation, the main infiltrating cells in are lymphocytes and macrophages. PMN responses in bacterial uveitis caused by the pathogens listed above have not yet been explored in animal models.

\subsection{Endotoxin-Induced Uveitis}

Endotoxin-induced uveitis (EIU) is an animal model that is used for studying the inflammatory mechanisms in infectious uveitis. EIU is initiated by using non-antigen-specific stimuli. This model also serves as a useful example of human uveitis. The lipid A moiety of bacterial endotoxin causes biological activity and effects such as hypotension and fever. Endotoxin as an inducer of uveitis was first used in 1943 when Ayo [136] demonstrated that a lone intravenous injection of endotoxin could cause inflammation in the eye in large laboratory animals.

Kinetic studies in mice showed that PMNs first migrated into the eye at approximately $6 \mathrm{~h}$ after endotoxin injection. Ocular inflammation peaked about $18 \mathrm{~h}$ later, suggesting that these PMNs were the main contributing factor to uveitis inflammation. Whitcup et al. [137] reported high Mac-1 expression on infiltrating PMNs and mononuclear cells $12 \mathrm{~h}$ after endotoxin injection. In Salmonella typhimurium endotoxin-injected mice, treatment with an anti-Mac1 antibody greatly reduced inflammatory cell infiltration in the uvea and lowered the inflammation grade compared to inflammation in control mice that were not treated with the antibody [138]. Li et al. [139] observed that caveolin-1, a protein of caveolae membrane microdomains, is involved in PMN recruitment in inflammation in EIU. This group measured the number of PMNs infiltrating to the intraocular space following the injection of S. typhimurium LPS in WT and caveolin-1 (Cav-1)-deficient mice. Cav-1 deficiency caused a significantly increased recruitment of immune cells and increased leukostasis compared with controls (Figure 6). The authors hypothesized that the Cav-1 deficiency rendered the retinal vasculature more permeable, since Cav-1 is a component of transendothelial and trans-RPE pores, which promote immune cell transmigration [139].

Inflammation in EIU is linked to the release of cytokines, such as TNF- $\alpha$, interleukin-1 (IL-1), IL-6, and IL-8 [140,141]. Endotoxins also prime PMNs for the release of leukotriene B4, which is important for further recruitment of PMNs, and has been observed in an EIU rat model [142]. Clearly, these studies using the EIU model support PMNs playing a significant role in inducing inflammation during bacterial uveitis.

Interestingly, pre-exposure to an endotoxin such as LPS causes reduced sensitivity to a second LPS challenge. This phenomenon is referred to as endotoxin tolerance. In the EIU model, repeated LPS injections into the footpad causes LPS tolerance and resistance to developing uveitis [143,144]. LPS is chemotactic for PMNs, and after challenging an animal with LPS a second time, PMN infiltration is inhibited dramatically [145]. Chang et al. [146] reported that in patients with acute anterior uveitis, peripheral blood PMNs and monocytes may exhibit endotoxin tolerance. This suggests that there are systemic factors that might be involved in the development of EIU tolerance. To further understand this mechanism, Mashimo et al. [147] used the LPS-tolerant EIU rat model and found that the reduction of peripheral blood PMN chemotaxis and constant high expression of IL-10 in the eye contributes to LPS tolerance. 


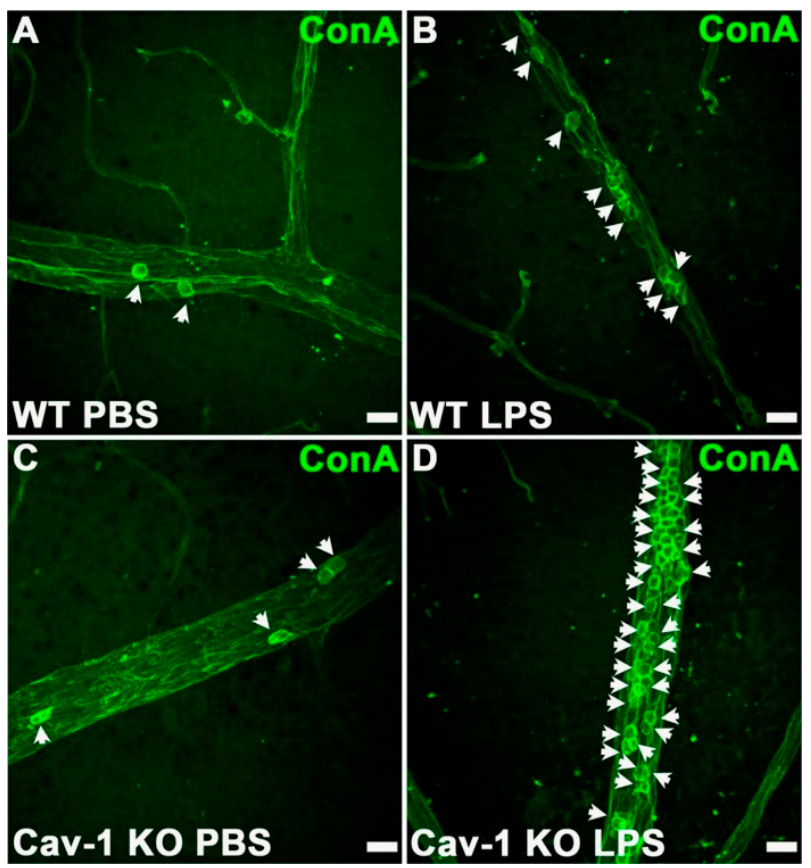

Figure 6. Caveolin-1 deficient mouse retinas show increased leukostasis when challenged with LPS. White arrows point to leukocytes. This figure is reproduced from Li et al. [139] with permission from the Association for Research in Vision and Ophthalmology.

\subsection{Uveitis Conclusions}

The EIU model in rodents mimics many immunopathogenic mechanisms that are associated with human uveitis, which is important in extrapolating data to human disease, and testing and developing novel therapies. Many EIU protocols utilize mouse models. This includes LPS injections into the eye, tail vein, footpad, and skin. The LPS-induced EIU model conveniently induces EIU within hours in mice, which makes this model appropriate for the studying basic mechanisms and possible therapeutic strategies. These models have been useful in studying PMN responses, such as migration and ROS release, in uveitis [139,142]. Some limitations to this model are the varied injection methods and routes, as well as the use of LPS preparations of different bacteria that may generate inconsistencies in experimental outcomes, and questions when extrapolating data from one uveitis model to another.

\section{Endophthalmitis}

Bacterial endophthalmitis is an infection and inflammation that occurs when microorganisms are introduced into the posterior segment of the eye. Endophthalmitis may follow intraocular surgery (postoperative), a penetrating injury to the eye (post-traumatic), or from metastatic spread of bacteria into the eye from a different anatomical site (endogenous). During infection, irreversible damage to retinal tissues frequently occurs. Inflammation and vision loss are devastating consequences of this infection (Figure 7).

The incidence of endophthalmitis after trauma has been estimated to occur in $3-17 \%$ of cases [33,148-150]. After cataract surgeries, which are the most common type of ocular surgery performed, the occurrence rate ranges from $0.056 \%$ to $0.57 \%$ [151]. Despite the low rate, this infection poses a significant health risk due to the large number of cataract surgeries performed each year. The World Health Organization estimates that the number of cataract surgeries will rise to 32 million per year by 2020 [152]. The range of the microorganisms causing endophthalmitis differs in various parts of the world. Gram-positive bacteria, including Bacillus, Staphylococcus, Streptococcus, Enterococcus, and other Gram-positive species cause over 75\% of culture positive cases of endophthalmitis in Western countries [153,154], while Gram-negative species comprise only $6 \%$ of endophthalmitis cases. In Far 
Eastern countries, Gram-positive bacteria account for approximately $53 \%$ of postoperative cases, and up to $26 \%$ may be caused by Gram-negative bacteria [152-156]. Endophthalmitis can also be a complication of keratitis, since keratitis can result in perforation of the cornea and contamination of the interior of the eye with the infecting organism [157].
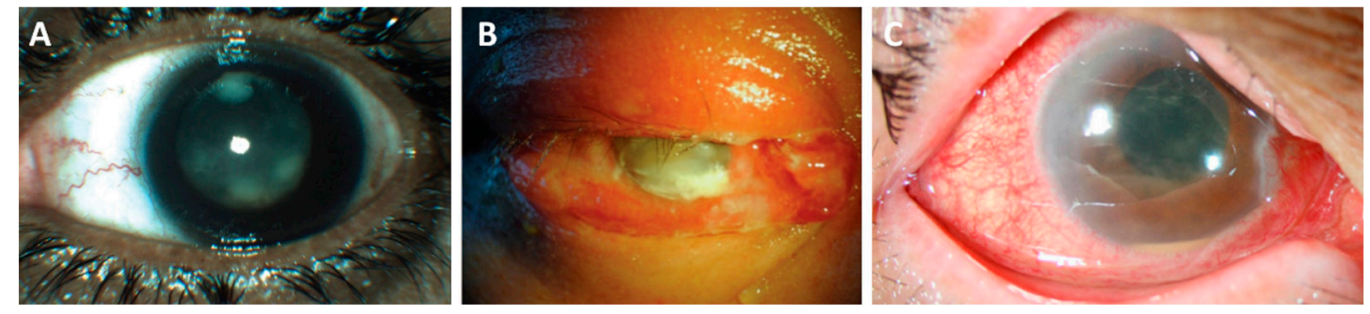

Figure 7. S.aureus, Bacillus, and E. faecalis endophthalmitis. (A) S. aureus endogenous endophthalmitis presenting with exudate behind the lens. (B) A patient with post-traumatic Bacillus endophthalmitis presents with chemosis, corneal opacification, periorbital swelling, proptosis, and a corneal ring abscess. (C) A patient with post-operative E. faecalis endophthalmitis presents with exudative membrane and infiltrates, ocular injection, and a hypopyon. This figure is reproduced under a Creative Commons Attribution-NonCommercial-ShareAlike License from (C) 2019 Indian Journal of Ophthalmology [158], the Creative Commons Attribution-ShareAlike License 4.0 from (C) 2017 Medicine [159], and the Creative Commons Attribution-NonCommercial 3.0 Unported from (C) 2015 J Korean Ophthalmol Soc [160].

Ocular damage is caused by both the bacteria and by the immune response. Indeed, bacterial growth and direct toxicity from bacterial products cause damage to host tissue, but the excessive inflammatory response may also be responsible for decreased visual outcome due to retinal toxicity from noxious PMN products. Many retinal cell types do not regenerate, so it is essential to reduce the damage caused by inflammation due to infiltrating PMNs, which are the predominant inflammatory cell type in the eye during the earliest stages of bacterial endophthalmitis [10,161-164]. The initial inflammatory response is unavoidable and may be the earliest sign of visual disturbance for the patient. Clearance of bacteria from the eye is vital and depends on an intricate host response characterized by the early recruitment of PMNs into the eye. Bacterial clearance by PMNs occurs via a coordinated effort of multiple activities, such as phagocytosis, and the release of reactive oxygen intermediates and granule enzymes (cathepsin G, myeloperoxidase [MPO], lactoferrin, and elastase). These products of PMN activation may cause enhanced tissue damage [165]. Therefore, PMN activities and their products designed to clear infections are likely in part responsible for retinal toxicity and subsequent vision loss in endophthalmitis.

\subsection{Staphylococcus aureus Endophthalmitis}

S. aureus is a chief cause of post-traumatic and postoperative endophthalmitis. The visual outcome of the disease is usually poor, and many cases result in final visual acuities of 20/400 or worse [151,166-168]. The development of antibiotic resistance in clinical isolates may result in an increased incidence of treatment failures for S. aureus endophthalmitis $[169,170]$.

S. aureus secretes many extracellular toxins, which include cell wall-associated proteins/adhesins (clumping factor, protein $\mathrm{A}$, and fibrinogen and fibronectin-binding proteins) and extracellular virulence factors (pore-forming toxins, lipases, and proteases). These secreted and cell wall components induce inflammation and likely direct toxicity on important tissues responsible for vision during S. aureus endophthalmitis. The effects of staphylococcal factors on intraocular inflammation were initially examined by injecting metabolically inactive bacteria, purified bacterial cell walls, and culture supernatants into rabbit eyes [161]. The injection of metabolically inactive bacteria or cell walls caused less inflammation and infiltration of PMNs compared to eyes injected with live bacteria or cell-free supernatants. Live bacteria and culture supernatants were also more toxic for the retina than cell walls or metabolically inactive bacteria, which suggests that retinal tissue damage was caused by secreted 
toxin(s) [161]. Individual staphylococcal cell wall components may also be important in driving inflammation in endophthalmitis. Suzuki et al. [171] reported the significant blunting of intraocular inflammation following infection with a tarO-deficient $S$. aureus mutant. This mutant was deficient in wall teichoic acids, suggesting that this cell wall component is important in inflammation during $S$. aureus endophthalmitis.

The roles of individual toxins in S. aureus endophthalmitis were first examined by comparing infections with mutant strains deficient in $\alpha-, \beta-$, or $\gamma$-toxin to infections caused by a WT parental strain in a rabbit model of endophthalmitis [148]. Of these toxins, the absence of $\alpha$-toxin resulted in the preservation of retinal function. The PMN response to infection with these strains was not investigated. Kumar and Kumar [172] later assessed the role of individual S. aureus cell wall components and cell surface or secreted proteins in mouse eyes. These included peptidoglycan, lipotechoic acid, heat-killed S. aureus, $\alpha$-toxin, protein A, and toxic shock syndrome toxin 1 . Purified virulence factors injected into the eyes of mice induced inflammation and a concentration-dependent release of cytokines and chemokines, including IL-6, IL-1 $\beta$, TNF- $\alpha, \mathrm{KC}$, and MIP- 2 in mouse eyes. This correlated with increased PMN infiltration, vascular leakage, and reduced retinal function (Figure 8) [172]. Although it is not known whether the specific concentrations of toxins injected into mouse eyes are replicated in experimental or human cases of endophthalmitis, this study showed that the injection of these purified toxins into the eye could cause changes similar to those observed during clinical infections.

Gamma-toxin and Panton-Valentine leukocidin (PVL) are two-component leukotoxins of S. aureus. Components of these toxins are able to interact with each other to form hybrid toxins. When these were injected into the rabbit vitreous, significant retinal toxicity occurred. Rabbit eyes injected with PVL alone had an increased infiltration of PMNs [173]. Although these results showed that leukotoxins have significant intraocular inflammatory activity, further studies are needed to determine the effects of $S$. aureus leukotoxins on PMNs during endophthalmitis.

The important role of secreted toxins in virulence during S. aureus endophthalmitis is supported by studies examining the genetic regulators that are responsible for the production of secreted proteins. In S. aureus, virulence factor expression is regulated by quorum-sensing systems. These regulators function at the transcriptional level, and are termed Agr (accessory gene regulator) and Sar (staphylococcal accessory regulator) [174], among others. In experimental comparisons of S. aureus endophthalmitis with WT or global regulatory mutants, regulatory mutant virulence was reduced or absent $[164,175,176]$. Importantly, there was also less PMN infiltration in the eyes of mice infected with the regulatory mutants $[164,175,176]$. This suggests that toxins under regulatory control contributed to some degree to the induction of inflammation and infiltration of PMNs. $\alpha$-toxin has been shown to induce the lysis of leukocytes, such as PMNs, after local injection, and even induce death after systemic injection in animals [177].

The recruitment of PMNs can be modulated during active S. aureus endophthalmitis. Giese et al. [178] demonstrated this by treating with anti-PMN antibodies (dAb) in a rat model. Treatment with $\mathrm{dAb}$ resulted in a temporary reduction in PMN infiltration, as well as subsequent reduction in intraocular inflammation in the initial course of $S$. aureus endophthalmitis. However, depleting PMNs also resulted in increased numbers of intraocular bacteria. Engelbert and Gilmore [9] reported that FasL, which was thought to negatively regulate the immune response in the eye, actually promoted the clearance of $S$. aureus. When mice deficient in FasL were infected intravitreally with S. aureus, the number of recruited granulocytes was decreased compared to infected eyes with FasL. Eyes lacking a functional FasL also had increased bacterial burden and retinal damage [9]. Rajamani et al. [179] investigated the global metabolomic regulation of innate immunity in S. aureus-infected mouse eyes. This led this group [180] to investigate the role of AMP-activated protein kinase (AMPK). AMPK is a multi-substrate protein kinase that contributes to regulating various metabolic processes. AMPK is downregulated in S. aureus-infected mouse eyes, but restoring its expression reduced the bacterial burden and inflammation in S. aureus-infected eyes by preventing NF-kB and MAP kinase signaling. Restoring its expression in vitro also increased PMN phagocytosis and the killing of 
staphylococci [180]. Retinal transcriptome analysis revealed major inflammatory/immune pathways impacted in a mouse model of S. aureus endophthalmitis. JAK/Stat and IL-17A signaling were the most significantly affected [179]. The contributions of those pathways to bacterial endophthalmitis have not yet been addressed, but IL-17 has been shown to induce protective innate immunity against S. aureus skin infection and to contribute to the production of antimicrobial peptide/PMN-recruiting chemokines [181,182]. IL-17 has also been studied in fungal keratitis in which PMNs were the cellular source of IL-17 [183,184]. These studies demonstrated the importance of inflammation and inflammatory pathways in S. aureus endophthalmitis.

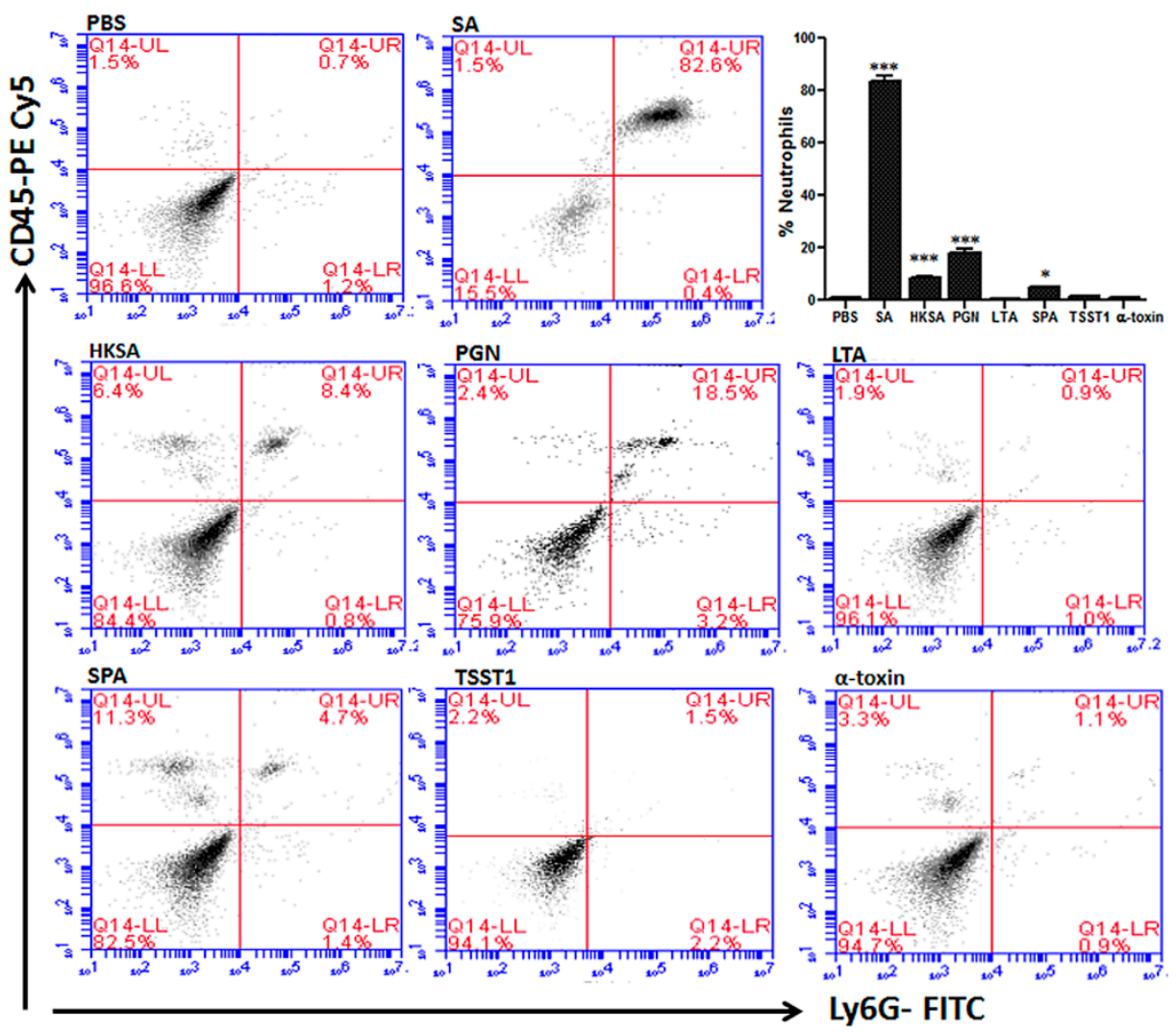

Figure 8. PMN infiltration into mouse retinas following the injection of $S$. aureus virulence factors. Mouse eyes injected with PBS, S. aureus (SA), heat-killed S. aureus (HKSA), peptidoglycan (PGN), lipotechoic acid (LTA), staphylococcal protein A (SPA), toxic shock syndrome toxin 1 (TSST1), or $\alpha$-toxin, and flow cytometry was performed to quantify retinal PMNs. This figure from Kumar and Kumar [172] is reproduced under a Creative Commons License from (C) 2015 PLoS ONE.

\subsection{Streptococcus pneumoniae Endophthalmitis}

Although Staphylococcus species cause the majority of cases of bacterial endophthalmitis, Streptococcus species are also a significant cause of infections that result in rapid vision loss $[148,151,185]$. S. pneumoniae has been reported as a main cause of endophthalmitis after ocular surgery, and is one of the main organisms cultured in bleb-associated endophthalmitis [186-190]. Streptococcal species are most often isolated from endophthalmitis cases in patients receiving intravitreal injections when physicians did not utilize facial masks [191]. Unfortunately, the majority of eyes infected with $S$. pneumoniae experience complete vision loss, despite aggressive therapy.

PMNs infiltrate into the eye at approximately $12 \mathrm{~h}$ after the injection of S. pneumoniae into rabbit eyes [192]. After $48 \mathrm{~h}$ postinfection, PMN numbers increased substantially, contributing to ocular damage. As with S. aureus endophthalmitis, the virulence factors of $S$. pneumoniae also contribute to endophthalmitis pathology. The polysaccharide capsule and cell wall components have been suggested as important virulence factors in S. pneumoniae intraocular infection [193]. In contrast to 
its limited importance in keratitis, the polysaccharide capsule of $S$. pneumoniae has been shown to be essential for full virulence in endophthalmitis [125,193]. As previously stated, the capsule has a known function of allowing pneumococci to evade phagocytosis [45,193]. In a rabbit endophthalmitis model, a capsule-deficient mutant of a S. pneumoniae clinical isolate was compared to its isogenic strain [193]. Although both animal groups had severe infections, less infiltration of inflammatory cells was observed in capsule-deficient mutant-infected eyes compared with eyes infected with the WT strain. The authors noted that the inflammation in the eyes infected with the parent strain was more distinct and damaging than in the mutant-infected eyes. The observation of fewer PMNs in the mutant-infected eyes was reflected by reduced myeloperoxidase (MPO) activity. Interestingly, this study showed significantly more bacteria in WT-infected eyes, which suggested better bacterial clearance in mutant-infected eyes. Together, these data support the argument that the capsule is important for both increasing PMN recruitment and in escaping PMN bacterial clearance during endophthalmitis [194,195]. This group [195] reported that rabbits passively immunized with Pneumovax ${ }^{\circledR} 23$ (a pneumococcal capsule-based vaccine) had less PMN in the vitreous compared to rabbits immunized with mock serum. The lack of PMNs in the vitreous resulted in higher bacterial loads in the immunized rabbits than mock-treated rabbits.

Attention has focused on S. pneumoniae virulence factors, specifically PLY [192,195-198]. PLY was first implicated as a virulence factor in a rat model of endophthalmitis in which purified PLY was intravitreally injected into eyes at different doses. $\mathrm{Ng}$ et al. [196] reported that purified PLY induced a dose-dependent influx of PMNs and retinal damage. This group [197] compared the virulence of a mutant S. pneumoniae strain deficient in PLY activity to a WT strain in a rat endophthalmitis model. Endophthalmitis from S. pneumoniae deficient in PLY activity resulted in less inflammation $24 \mathrm{~h}$ postinfection compared to an infection from a strain with full PLY activity. However, by $48 \mathrm{~h}$, there was no difference clinically and histologically between PLY-deficient and WT strains, regardless of toxin production. Sanders et al. [199] conducted a similar study in a rabbit endophthalmitis model with clinical S. pneumoniae strains that had low or high PLY activity. These results were similar to that in the rat model, in which there was a reduced infiltration of PMNs in eyes infected with a low activity of PLY compared to eyes infected with a high activity of PLY [192]. Sanders et al. [199] also reported that immunizing rabbits with PLY reduced the number of PMN in the vitreous, which resulted in greater bacterial load in the vitreous. Overall, these studies support the idea that PLY contributes to pathogenesis during the early stages of S. pneumoniae endophthalmitis.

Autolysin has been studied in S. pneumoniae endophthalmitis as well. This enzyme is thought to contribute to meningitis virulence by facilitating the release of inflammatory cell wall components and PLY when cells autolyze [200,201]. An autolysin-deficient strain of S. pneumoniae resulted in reduced inflammation and PMN infiltration at $24 \mathrm{~h}$ postinfection compared to infection caused by a WT strain in an endophthalmitis model [197]. The direct mechanisms by which PLY and autolysin contribute to inflammation and PMN infiltration in endophthalmitis require further investigation.

\subsection{Bacillus Endophthalmitis}

Bacillus is one of the major bacterial pathogens causing post-traumatic endophthalmitis, and is also known for causing endogenous endophthalmitis in intravenous drug abusers [202-204]. A majority of Bacillus endophthalmitis cases have a rapid course, which usually results in blindness within a few days [203,204]. Bacillus cereus is the most common Bacillus species isolated from blinding cases of endophthalmitis. Bacillus endophthalmitis can also be caused by Bacillus thuringiensis, which is a fellow member of the Bacillus cereus sensu lato (BCSL) group that is both genetically and phenotypically analogous to B. cereus [205]. The hallmarks of Bacillus endophthalmitis include rapidly evolving intraocular inflammation, eye pain, a rapid loss of visual acuity, and fever. Fortunately, Bacillus species have remained sensitive to currently used ophthalmic antibiotics. However, the rapidly destructive nature of Bacillus endophthalmitis calls for immediate and proper treatment, which may include intravitreal injections, systemic antibiotics, and vitrectomy. 
As previously discussed, PMNs are a predominant infiltrating cell type that are the first line of defense in innate immunity against intraocular pathogens. In Bacillus endophthalmitis in rabbits, PMN were observed in the vitreous in close proximity to the optic nerve at $6 \mathrm{~h}$ postinfection, with PMN migrating into the vitreous from the ciliary body shortly thereafter [148]. Similar observations were reported in a mouse model of Bacillus endophthalmitis, initiating as early as $4 \mathrm{~h}$ postinfection in the same anatomical areas of the eye [10]. Histology, MPO, and flow cytometry confirmed that the main infiltrating cell in experimental Bacillus endophthalmitis is the PMN [10].

PMNs function not only as phagocytes, but also synthesize and release chemokines and cytokines, including TNF $\alpha$ [206]. During Bacillus intraocular infection, TNF $\alpha$ is detected prior to and during PMN presence in the eye [10], and is important to intraocular pathogen control during experimental Bacillus endophthalmitis. Ramadan et al. [207] reported that the absence of TNF $\alpha$ in a mouse model of Bacillus endophthalmitis resulted in fewer PMNs migrating into the eye, which resulted in faster retinal function loss and bacterial replication. In this study, IL-6, IL-1 $\beta$, and MIP- $1 \alpha$ were detected during the later stages of infection when large numbers of PMNs were present [206]. To test whether the chemokine CXCL1 or the cytokine IL-6 contributed to PMN recruitment, Parkunan et al. [208] compared Bacillus endophthalmitis pathogenesis in WT, IL-6-deficient, and CXCL1-deficient mice. While the absence of IL-6 did not change the overall pathogenesis of endophthalmitis, the absence of CXCL1 resulted in less PMN infiltration and retinal damage. Interestingly, the bacterial burden did not increase in the absence of CXCL1 [208]. This finding is contrary to what has been seen in other ocular infections, such as keratitis, where a reduction of PMNs led to a greater bacterial burden [77].

Similar findings were observed in mice lacking functional innate immune receptor pathways. TLRs, specifically, TLR2 is a Gram-positive pathogen recognition receptor. TLR2-deficient mice with Bacillus endophthalmitis had a delayed recruitment of PMN and less inflammation in the eye, which was likely due to the altered expression of recruiting cytokines and chemokines. Similar to the CXCL1-deficient mice, the absence of TLR2 did not change the growth of Bacillus in the eye [209]. Although these studies showed reduced inflammation in TLR2-deficient mice, there was residual inflammation, suggesting the contribution of further innate immune recognition and signaling mechanisms in inflammation. These findings spurred on studies by Parkunan et al. [210] to examine the role of TLR4 and its adaptor molecules, TRIF and MyD88, in Bacillus endophthalmitis. Although Bacillus does not synthesize the canonical TLR4 ligand, LPS, TLR4-deficient, MyD88-deficient, and TRIF-deficient mice each had reduced inflammation and reduced recruitment of PMNs after Bacillus intraocular infection. TLR4-deficient mice were also used in a study showing that TLR4 was important for driving the expression of proinflammatory mediators that stimulated acute inflammation and PMN recruitment in Bacillus endophthalmitis [211]. These findings suggested a possible benefit in targeting CXCL1, TLR2, and/or TLR4 to control inflammation during Bacillus endophthalmitis and possibly other bacterial intraocular infections.

Bacillus has several virulence factors, many of which are expressed during endophthalmitis, such as cell wall components, hemolysins, phospholipases, and proteases. Individual toxins have been analyzed using mutants deficient in those toxins in experimental models of Bacillus endophthalmitis $[162,163,212]$. Bacillus toxins contribute not only to intraocular damage, but also to acute inflammation via the recruitment of inflammatory cells to the vitreous [10]. Beecher et al. [212] used a rabbit model with purified hemolysin BL (HBL) to show that the injection of this toxin into rabbit eyes caused less PMN infiltration than eyes injected with crude Bacillus exotoxin preparations containing many secreted proteins. Later, Callegan et al. [213] used a rabbit model of Bacillus endophthalmitis to show that HBL contributed minimally to PMN recruitment. Rabbit eyes infected with an HBL-deficient mutant had similar PMN infiltration compared to that of WT Bacillus-infected eyes [213]. Phosphatidylcholine-specific phospholipase C (PC-PLC) was toxic when injected into rabbit eyes [214]. However, Callegan et al. [162] reported that PC-PLC and phosphatidylinositol-specific phospholipase C (PI-PLC) had minimal roles in the recruitment of inflammatory cells during Bacillus endophthalmitis. Rabbit eyes infected with PI-PLC-deficient or PC-PLC-deficient mutants had 
significantly less PMN infiltration at $12 \mathrm{~h}$ postinfection, but at $18 \mathrm{~h}$ postinfection, the number of PMNs in eyes infected with these mutants was similar to eyes infected with WT Bacillus [162]. The expression of most Bacillus toxins and enzymes is controlled by a quorum-sensing transcriptional regulator, PlcR. In an endophthalmitis rabbit model, PlcR mutants of B. cereus and B. thuringiensis were significantly less virulent than WT. The plcR-deficient mutants also delayed the onset of PMN infiltration during infection $[215,216]$. The reduced virulence in this study was likely due to the reduced expression of virulence factors by plcR-deficient strains. Together, these studies demonstrated the significance of quorum sensing, but perhaps not these individual toxins, to the pathogenicity of Bacillus endophthalmitis. Quorum sensing might be thought of as a potential therapeutic target for this disease.

Recently, Mursalin et al. [217] demonstrated that the S-layer protein of Bacillus contributed to the intraocular infiltration of PMN during endophthalmitis. Compared to infection with WT Bacillus, infection with a strain lacking the S-layer protein SlpA resulted in significantly less MPO and less PMN infiltration in infected mouse eyes. In fact, the SlpA mutation in Bacillus resulted in minimal inflammation similar to that observed with WT Bacillus infections in TLR2-deficient and TLR4-deficient mice $[209,210]$. The authors suggested that the S-layer contributed to PMN recruitment by triggering innate inflammatory pathways in the retina [217]. This was the first report of the absence of a single Bacillus virulence factor having such a profound impact on the severity of inflammation, suggesting the importance of the S-layer protein as a potential therapeutic target.

\subsection{Enterococcus faecalis Endophthalmitis}

E. faecalis is a Gram-positive organism and a human intestinal commensal that is among the leading causes of nosocomial infections [218]. E. faecalis is a hazardous bacterium that has acquired resistance to several available antibiotics. As such, E. faecalis is ranked seventh among the Centers for Disease Control and Prevention's (CDC's) top antibiotic-resistant threats [219]. E. faecalis is one of the leading causes of postoperative endophthalmitis, mainly resulting from infected filtering blebs after glaucoma surgery $[189,190]$. These clinical studies reported that $E$. faecalis is usually associated with a significant loss of vision, with only about $15 \%$ of endophthalmitis cases resulting in 20/200 or better visual acuity. The preceding studies indicated that enterococcal virulence factors such as gelatinase, cytolysin, and serine protease contributed to the pathogenesis of E. faecalis endophthalmitis [220-224], affecting the recruitment of PMNs to the eye. Stevens et al. [219] conducted the first study documenting an E. faecalis endophthalmitis animal model. The authors showed that a plasmid (pAD1) encoding a broad-spectrum cytolysin in E. faecalis contributed to the pathogenesis of endophthalmitis. After infecting rabbits with isogenic strains of E. faecalis that harbored or lacked a plasmid encoding the cytolysin, eyes infected with the strain lacking the pAD1 had less vitritis and PMN recruitment compared to strains with the plasmid encoding the cytolysin [220]. To further prove that this effect was due to the cytolysin and not any other virulence factors that may have been encoded on the pAD1, Jett et al. [221] tested mutants of E. faecalis strains containing Tn917 transposon insertions in different cytolysin genes in the rabbit endophthalmitis model. Rabbit eyes infected with mutants with Tn917 inserted into the cytolysin cylL gene had markedly less PMN recruitment [221]. Recent studies demonstrated that the activity of cytolysin and resulting intraocular inflammation were reduced following treatment with a biomimetic nanosponge that is capable of binding the large subunit of cytolysin, CylLL [222,225]. In sterile in vivo and in viable E. faecalis endophthalmitis mouse models, nanosponge treatment resulted in less inflammation and damage to the eye and preserved retinal function $[225,226]$. Therefore, the cytolysin is important in inflammation and PMN recruitment, although the mechanism by which cytolysin activates inflammatory pathways remains to be determined.

In E. faecalis, the Fsr quorum-sensing system regulates the expression of serine and gelatinase proteases in a cell density-dependent manner. Mylonakis et al. [222] reported that rabbit eyes infected with an $f s r B$-deficient mutant had mild PMN infiltrate into the vitreous, preserved retinal layer structure, and no subretinal inflammatory infiltrate compared to that of WT-infected eyes after $48 \mathrm{~h}$ postinfection. Engelbert et al. [222] later showed that rabbit eyes infected with E. faecalis serine protease-deficient and 
gelatinase-deficient mutants had less PMN infiltration and retinal damage than WT-infected rabbit eyes. Suzuki et al. [224] confirmed a role for the E. faecalis serine protease in a model of E. faecalis endophthalmitis in aphakic rabbits. The authors reported that aphakic rabbit eyes infected with the serine protease-deficient mutant had a delayed PMN influx and significantly less retinal damage. Similar results were observed after injecting culture supernatants from WT or protease-deficient $E$. faecalis. From these studies, it is clear that the Fsr quorum sensing system and the virulence factors it regulates contribute to inflammation and the recruitment of PMNs during E. faecalis endophthalmitis.

\subsection{Gram-negative Bacterial Endophthalmitis}

Gram-negative bacteria are more often associated with endogenous endophthalmitis than with other types of endophthalmitis. Gram-negative endophthalmitis has been reported to be more common than Gram-positive endophthalmitis in the Far East, while in Europe and North America, Gram-positive strains were more prevalent in this disease [227,228]. Common Gram-negative organisms isolated from endogenous endophthalmitis cases include Klebsiella pneumoniae, Pseudomonas aeruginosa, Escherichia coli, and Neisseria meningitidis. Unfortunately, the visual outcomes connected with these bacterial infections remain poor $[227,228]$.

The most frequently isolated serotypes in endogenous K. pneumoniae endophthalmitis are K1 and K2 [229]. K1 serotype strains contain mucoviscosity-associated gene A (magA) and regulator of mucoid phenotype $(r m p A)$ genes that have been reported to be significant virulence factors in liver abscesses [229-231]. From these abscesses, the bacteria can enter the bloodstream and infect the eye, causing endogenous endophthalmitis. Primary underlying K. pneumoniae liver abscesses have a $3 \%$ to $10 \%$ risk for metastatic spread to the eye [232,233]. Two-thirds of $K$. pneumoniae endogenous endophthalmitis patients had a liver abscess caused by the same bacteria, and half were diabetic. Additionally, clinical isolates often express the hypermucoviscous (HMV) phenotype [229-235]. Even after treatment, a majority of patients with K. pneumoniae endophthalmitis lose useful vision $[227,228,236-238]$.

In experimental K. pneumoniae endophthalmitis, mouse and rabbit eyes intravitreally injected with K. pneumoniae had an influx of PMNs from the optic nerve and ciliary body starting at $9 \mathrm{~h}$ postinfection [239]. An HMV-deficient K. pneumoniae isolate induced less retinal inflammation and function loss compared to eyes infected with a hypermucoviscous isolate. MPO analysis of these eyes suggested greater numbers of PMNs in eyes infected with the hypermucoviscous strain [240]. The significance of MagA in endophthalmitis and PMN recruitment was confirmed by Hunt et al. [241], who reported that mouse eyes infected with WT K. pneumoniae had greater PMN influx, which resulted in significantly more retinal function loss than eyes infected with an isogenic magA-deficient strain. These authors [242] also showed that TLR4 contributed to PMN recruitment during K. pneumoniae endophthalmitis. TLR4-deficient mouse eyes had reduced numbers of PMNs after 12 and $14 \mathrm{~h}$ postinfection compared to WT eyes infected with K. pneumoniae [242].

Escherichia coli and P. aeruginosa are also Gram-negative bacteria commonly isolated from endogenous endophthalmitis cases and are also associated with poor visual outcomes [227,228,243-245]. Other than the K. pneumoniae studies mentioned above, there have been few studies on the contributions of virulence factors to endophthalmitis caused by Gram-negative bacteria. Aizuss et al. [8] reported that an absence of complement via the injection of cobra venom factor in guinea pigs delayed PMN recruitment following the intravitreal injection of P. aeruginosa. Astley et al. [239] reported that while inflammation in E. coli and K. pneumoniae endophthalmitis was severe at $15 \mathrm{~h}$ postinfection in mice, inflammation was not as pronounced in rabbit at the same time point postinfection. Overall, the number of studies examining PMN responses in in vivo models of Gram-negative endophthalmitis has been limited. 


\subsection{Endophthalmitis Conclusions}

Therapies for bacterial endophthalmitis, including antibiotics and anti-inflammatory drugs, are only effective when given promptly after disease onset to kill microorganisms and limit inflammation and ocular injury [33]. However, current therapies often fail to completely arrest inflammation and do not prevent toxins from damaging tissue and threatening retinal function $[71,225,226,239]$. Vision loss during endophthalmitis is a clinically relevant problem since there are currently no medical options to repair permanent retinal damage. More effective therapies are needed to mitigate inflammation and toxin production to decrease disease severity and prevent blindness during bacterial endophthalmitis.

From the studies presented above, it may be useful to target the cell wall components of bacteria, since these seem to be important for inducing inflammation by activating TLRs. However, it should be noted that the cell wall components of some bacteria that are important for inflammation in endophthalmitis are not important for inflammation in other ocular infections and vice versa (i.e., protein A of S. aureus or the capsule of S. pneumoniae). Of course, the models and experimental parameters are different among many studies, which may confound comparisons. Bacterial quorum-sensing mechanisms also seem to be important in the degree of resulting inflammation during endophthalmitis. Targeting these transcriptional regulators instead of single virulence factors may help to reduce the inflammation in these diseases. Targeting important inflammatory pathways on the host side may be beneficial as well. For instance, inducing the expression of AMPK, FasL, or antimicrobial peptides may be helpful in the clearance of bacteria by promoting PMN recruitment and phagocytic activity/bacterial killing, respectively.

\section{Concluding Remarks}

In recent years, a considerable amount of research on the recruitment, regulation, and responses of PMNs has been conducted in different but complementary models of bacterial ocular infections. This work has led to a deeper understanding of the varied biological roles of this inflammatory cell and the bacterial and host factors that influence its recruitment and function (Figure 9) (Table 1). Studies so far strongly suggest that PMN activity is important for bacterial clearance, but in many cases, the mechanisms underlying PMN involvement in ocular infection are not fully understood. The complexity of the immune regulation in the ocular environment does affect PMN activity, and it may be important to target these regulation systems in order to induce a more effective bacterial clearance. These studies also show that targeting bacterial virulence factors is important to mitigate overall inflammation. Many of these virulence factors have properties that are important in circumventing PMN function. Most of the factors discussed in this review also have an importance in inducing PMN recruitment, which could be understood as beneficial since these inflammatory cells are important for bacterial clearance. However, these factors and PMNs also contribute to host tissue damage. To avoid this Pyrrhic Victory scenario, an effective therapy would need to include components that kill bacteria, clear virulence factors that may be left behind, and perhaps induce PMN activity that would clear remaining bacteria with little to no damage to host tissue. Overall, further investigations on the function of PMNs in response to bacterial ocular infection should open new perspectives for a better understanding of the interplay of PMNs with bacteria within the ocular environment. 


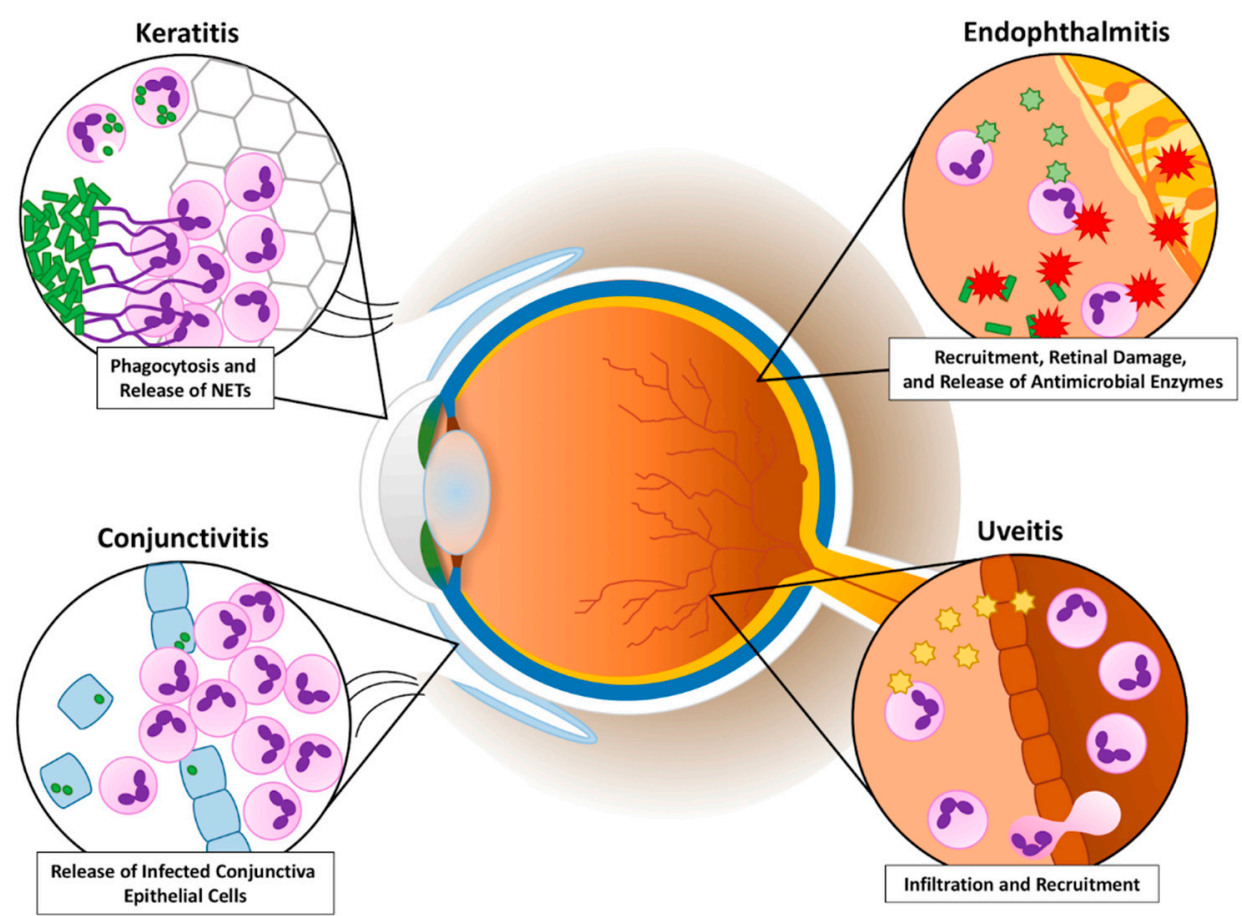

Figure 9. Summary of PMN responses to ocular bacterial infections. This figure illustrates PMN responses that have been observed in the different areas of the eye during conjunctivitis, keratitis, uveitis, and endophthalmitis. During conjunctivitis, PMNs damage the conjunctival epithelial barrier by accumulating and releasing infected epithelia onto the surface of the conjunctiva. The presence of PMNs during this infection causes a decrease in transforming growth factor-beta (TGF- $\beta$ ) and interleukin- 5 (IL-5), which is suggested to downregulate IgA humoral responses [26,56]. The PMN response during keratitis includes a release of neutrophil extracellular traps (NETs) to prevent the further dissemination of bacteria. PMNs have also been observed to bacteria in the cornea and produce IL-1 $\beta$ and IL-17 as part of their response $[80,83,99,120,183,184]$. In some uveitis models, PMNs are recruited quickly into the eye, and self-recruit by producing LTB4 and other proinflammatory molecules [133,142]. PMNs in the endophthalmitis also self-recruit by releasing recruiting chemokines such as TNF- $\alpha$, but may also cause retinal damage by producing antimicrobial enzymes and reactive oxygen species (ROS) $[10,206]$. 
Table 1. Summary of bacterial components, PMN responses, and inflammatory pathways and cytokines involved in bacterial ocular infections. MyD88: myeloid differentiation primary response 88, SP-D: surfactant protein D, TLR: Toll-like receptor.

\begin{tabular}{|c|c|c|c|c|}
\hline Bacterial Pathogen & Bacterial Components & PMN Response & Inflammatory Pathways & $\begin{array}{l}\text { Cytokines and } \\
\text { Chemokines }\end{array}$ \\
\hline \multicolumn{5}{|c|}{ Conjunctivitis } \\
\hline S. aureus & PNAG [37] & Infiltration [25,35-37] & & \\
\hline S. pneumoniae & $\begin{array}{c}\text { Polysaccharide capsule } \\
{[47,50]}\end{array}$ & Infiltration [47] & & \\
\hline C. trachomatis & & $\begin{array}{c}\text { Infiltration }[26,55,56] \\
\text { Damage to epithelia [26] }\end{array}$ & & TGF- $\beta$ and IL-5 [26] \\
\hline \multicolumn{5}{|c|}{ Keratitis } \\
\hline P. aeruginosa & $\begin{array}{c}\text { T3SS [80] } \\
\text { ExoS and ExoT [72,81] } \\
\text { Flagellum [82] }\end{array}$ & $\begin{array}{c}\text { Infiltration } \\
{[63,76-80,82,84]} \\
\text { NETosis [80] } \\
\text { Apoptosis [81] }\end{array}$ & $\begin{array}{l}\text { MyD88 [79] } \\
\text { NF-kB [82] } \\
\text { TLR5 [82] } \\
\text { IKB- } \alpha[82] \\
\text { SP-D [97,98] }\end{array}$ & $\begin{array}{l}\text { IL-6, IL-8, and } 1 \beta \text { [82] } \\
\text { CCL2 and CCL3 [84] }\end{array}$ \\
\hline S. aureus & $\begin{array}{c}\text { Peptidoglycan [93] } \\
\text { Cysteine proteases [99] } \\
\alpha \text {-toxin }[88,91,100,101] \\
\beta \text {-toxin }[91] \\
\gamma \text {-toxin }[104] \\
\text { Protein A }[88,105] \\
\end{array}$ & $\begin{array}{c}\text { Infiltration } \\
{[88,91,94-96,104]} \\
\text { Phagocytosis [99] }\end{array}$ & $\begin{array}{c}\text { TLR2 [93,94] } \\
\text { MyD88 [94] } \\
\text { MAPKs [93] } \\
\text { NF-kB [93] } \\
\text { ICAM-1 [95] } \\
\text { SP-D [99] }\end{array}$ & $\begin{array}{c}\text { TNF } \alpha[93] \\
\text { IL-6, IL-8, TNF- } \alpha[93,96] \\
\text { CXCR2 }[95,96]\end{array}$ \\
\hline S. pпеитопіае & $\begin{array}{c}\text { Pneumolysin } \\
{[11,115-120]}\end{array}$ & $\begin{array}{c}\text { Infiltration [116,117] } \\
\text { Corneal damage [115] }\end{array}$ & $\begin{array}{c}\text { NLRP3/ASC [120] } \\
\text { Caspase-1 [120] }\end{array}$ & IL-1 $\beta$ [120] \\
\hline \multicolumn{5}{|c|}{ Endophthalmitis } \\
\hline S. aureus & $\begin{array}{c}\text { Lipotechoic acids } \\
\text { [171,172] } \\
\alpha \text {-toxin [148] } \\
\beta \text {-toxin [148] } \\
\gamma \text {-toxin [148,173] } \\
\text { Peptidoglycan [172] } \\
\text { Protein A [172] } \\
\text { TSST-1 [172] } \\
\text { PVL [173] }\end{array}$ & $\begin{array}{c}\text { Infiltration } \\
{[161,172,173,178]}\end{array}$ & $\begin{array}{c}\text { FasL [9] } \\
\text { Complement [9] }\end{array}$ & $\begin{array}{c}\text { IL-6 and } 1 \beta[172] \\
\text { TNF } \alpha[172] \\
\text { KC [172] } \\
\text { MIP2 [172] }\end{array}$ \\
\hline S. pпеитопіае & $\begin{array}{c}\text { Polysaccharide capsule } \\
\text { [193,199] } \\
\text { Pneumolysin } \\
{[192,196,197,199]} \\
\text { Autolysin }[197]\end{array}$ & Infiltration [192,193] & & \\
\hline Bacillus & $\begin{array}{c}\text { Hemolysin BL }[212,213] \\
\text { PC-PLC [162,214] } \\
\text { PI-PLC [162] } \\
\text { S-layer [217] }\end{array}$ & Infiltration $[10,148,207]$ & $\begin{array}{c}\text { TLR2 [209] } \\
\text { TLR4 [210] } \\
\text { MyD88 [210] } \\
\text { TRIF [210] } \\
\text { NOD2, NLRP3 [239] }\end{array}$ & $\begin{array}{c}\text { TNF } \alpha[10,207] \\
\text { IL-6 and IL-1 } \beta \\
{[207,208,210]} \\
\text { MIP-1 } \alpha[207] \\
\text { CXCL1 }[208,210]\end{array}$ \\
\hline E. faecalis & $\begin{array}{c}\text { Gelatinase }[222,224] \\
\text { Cytolysin }[220,221,225] \\
\text { Serine protease }[222,224]\end{array}$ & Infiltration [221-224] & & \\
\hline K. pneuтопіае & $\begin{array}{l}\text { HMV phenotype } \\
{[230,236,240-242]}\end{array}$ & Infiltration $[238,239,241]$ & TLR4 [242] & $\begin{array}{c}\text { CXCL1, TNF, MIP-1 } \\
\text { [242] }\end{array}$ \\
\hline P. aeruginosa & & Infiltration [8] & & \\
\hline E. coli & & Infiltration [239] & & \\
\hline
\end{tabular}

Author Contributions: E.T.L. and M.C.C. outlined the topics covered in the review. E.T.L. wrote the draft of the manuscript. M.H.M. edited, added comments, and provided technical support for the manuscript. M.C.C. edited and added comments to the manuscript.

Funding: This work is supported by the National Institute of Health grants R01EY028810 and R01EY024140 (to MCC). Our research is also supported in part by the National Institute of Health grants R01EY025947 and R21EY028066 (to MCC), the National Eye Institutes Vision Core Grant P30EY021725 (to MCC), a Presbyterian Health Foundation Research Support Grant Award (to MCC), a Presbyterian Health Foundation Equipment Grant (to Robert E. Anderson, OUHSC), and an unrestricted grant to the Dean A. McGee Eye Institute from Research to Prevent Blindness. 
Acknowledgments: Special thanks to Darren Lee (University of Oklahoma Health Sciences Center [OUHSC] Department of Ophthalmology) for providing insight and advice on infectious uveitis models, and to Phillip Coburn (OUHSC Department of Ophthalmology) for providing editorial support.

Conflicts of Interest: The authors declare no conflict of interest.

\section{References}

1. Medawar, P.B. Immunity to Homologous Grafted Skin. III. The Fate of Skin Homografts Transplanted to the Brain, to Subcutaneous Tissue, and to the Anterior Chamber of the Eye. Br. J. Exp. Pathol. 1948, 29, 58-69. [PubMed]

2. Stein-Streilein, J. Immune Regulation and the Eye. Cell Press 2008, 29, 548-554. [CrossRef] [PubMed]

3. Taylor, A.W. Ocular Immunosuppressive Microenvironment. Chem. Immunol. Allergy 2007, 92, 71-85. [CrossRef] [PubMed]

4. Sabatino, F.; Di Zazzo, A.; De Simone, L.; Bonini, S. The Intriguing Role of Neuropeptides at the Ocular Surface. Ocul. Surf. 2017, 15, 2-14. [CrossRef]

5. Foulsham, W.; Coco, G.; Amouzegar, A.; Chauhan, S.K.; Dana, R. When Clarity Is Crucial: Regulating Ocular Surface Immunity. Trends Immunol. 2018, 39, 288-301. [CrossRef]

6. Garreis, F.; Gottschalt, M.; Paulsen, F.P. Antimicrobial Peptides as a Major Part of the Innate Immune Defense at the Ocular Surface. Dev. Ophthalmol. 2010, 45, 16-22. [CrossRef]

7. McDermott, A.M. Antimicrobial Compounds in Tears. Exp. Eye Res. 2013, 117, 53-61. [CrossRef]

8. Aizuss, D.H.; Mondino, B.J.; Sumner, H.L.; Derhlefs, B.A. The Complement System and Host Defense against Pseudomonas Endophthalmitis. Investig. Ophthalmol. Vis. Sci. 1985, 26, 1262-1266.

9. Engelbert, M.; Gilmore, M.S. Fas Ligand but Not Complement Is Critical for Control of Experimental Staphylococcus aureus Endophthalmitis. Investig. Ophthalmol. Vis. Sci. 2005, 46, 2479-2486. [CrossRef]

10. Ramadan, R.T.; Ramirez, R.; Novosad, B.D.; Callegan, M.C. Acute Inflammation and Loss of Retinal Architecture and Function during Experimental Bacillus Endophthalmitis. Curr. Eye Res. 2006, 31, 955-965. [CrossRef]

11. Karthikeyan, R.S.G.; Priya, J.L.; Leal, S.M.; Toska, J.; Rietsch, A.; Prajna, V.; Pearlman, E.; Lalitha, P. Host Response and Bacterial Virulence Factor Expression in Pseudomonas aeruginosa and Streptococcus pneumoniae Corneal Ulcers. PLoS ONE 2013, 8, 2-9. [CrossRef] [PubMed]

12. Dancey, J.T.; Deubelbeiss, K.A.; Harker, L.A.; Finch, C.A. Neutrophil Kinetics in Man. J. Clin. Investig. 1976, 58, 705-715. [CrossRef] [PubMed]

13. Ley, K.; Laudanna, C.; Cybulsky, M.I.; Nourshargh, S. Getting to the Site of Inflammation: The Leukocyte Adhesion Cascade Updated. Nat. Rev. Immunol. 2007, 7, 678-689. [CrossRef] [PubMed]

14. Rosales, C. Neutrophil: A Cell with Many Roles in Inflammation or Several Cell Types? Front. Physiol. 2018, 9, 1-17. [CrossRef]

15. Steadman, R.; Topley, N.; Jenner, D.E.; Davies, M.; Williams, J.D. Type 1 Fimbriate Escherichia coli Stimulates a Unique Pattern of Degranulation by Human Polymorphonuclear Leukocytes. Infect. Immun. 1988, 56, 815-822.

16. Fuchs, T.A.; Abed, U.; Goosmann, C.; Hurwitz, R.; Schulze, I.; Wahn, V.; Weinrauch, Y.; Brinkmann, V.; Zychlinsky, A. Novel Cell Death Program Leads to Neutrophil Extracellular Traps. J. Cell Biol. 2007, 176, 231-241. [CrossRef]

17. Fridlender, Z.G.; Sun, J.; Kim, S.; Kapoor, V.; Cheng, G.; Ling, L.; Worthen, G.S.; Albelda, S.M. Polarization of Tumor-Associated Neutrophil Phenotype by TGF- $\beta$ : "N1" versus "N2" TAN. Cancer Cell 2009, 16, 183-194. [CrossRef]

18. Mannis, M.; Plotnik, R. Bacterial Conjunctivitis; Tasman, W., Jaeger, E., Eds.; Lippincott Williams and Wilkins: Philadelphia, PA, USA, 2006.

19. Sheikh, A.; Hurwitz, B.; van Schayck, C.P.; McLean, S.; Nurmatov, U. Antibiotics versus Placebo for Acute Bacterial Conjunctivitis. Cochrane Database Syst. Rev. 2012, 9, CD001211. [CrossRef]

20. Alfonso, S.A.; Fawley, J.D.; Alexa Lu, X. Conjunctivitis. Prim. Care 2015, 42, 325-345. [CrossRef]

21. Smith, A.F.; Waycaster, C. Estimate of the Direct and Indirect Annual Cost of Bacterial Conjunctivitis in the United States. BMC Ophthalmol. 2009, 9, 13. [CrossRef] 
22. Azari, A.A.; Barney, N.P. Conjunctivitis: A Systematic Review of Diagnosis and Treatment. JAMA 2013, 311, 1721-1729. [CrossRef] [PubMed]

23. Høvding, G. Acute Bacterial Conjunctivitis. Acta Ophthalmol. 2008, 86, 5-17. [CrossRef] [PubMed]

24. Varu, D.M.; Rhee, M.K.; Akpek, E.K.; Amescua, G.; Farid, M.; Garcia-Ferrer, F.J.; Lin, A.; Musch, D.C.; Mah, F.S.; Dunn, S.P. Conjunctivitis Preferred Practice Pattern ${ }^{\circledR}$. Ophthalmology 2019, 126, P94-P169. [CrossRef] [PubMed]

25. Cvenkel, B.; Globocnik, M. Conjunctival Scrapings and Impression Cytology in Chronic Conjunctivitis. Correlation with Microbiology. Eur. J. Ophthalmol. 1997, 7, 19-23. [CrossRef]

26. Lacy, H.M.; Bowlin, A.K.; Hennings, L.; Scurlock, A.M.; Nagarajan, U.M.; Rank, R.G. Essential Role for Neutrophils in Pathogenesis and Adaptive Immunity in Chlamydia caviae Ocular Infections. Infect. Immun. 2011, 79, 1889-1897. [CrossRef]

27. Lee, K.W.; Jung, J.W. Systemic Minocycline Treatment of Methicillin-Resistant Staphylococcus aureus in Giant Fornix Syndrome. Korean J. Ophthalmol. 2016, 30, 394-395. [CrossRef]

28. Hu, V.H.; Holland, M.J.; Burton, M.J. Trachoma: Protective and Pathogenic Ocular Immune Responses to Chlamydia trachomatis. PLoS Negl. Trop. Dis. 2013, 7, e2020. [CrossRef]

29. Shine, W.E.; Silvany, R.; McCulley, J.P. Relation of Cholesterol-Stimulated Staphylococcus Aureus Growth to Chronic Blepharitis. Investig. Ophthalmol. Vis. Sci. 1993, 34, 2291-2296.

30. Wong, V.W.Y.; Lai, T.Y.Y.; Chi, S.C.C.; Lam, D.S.C. Pediatric Ocular Surface Infections: A 5-Year Review of Demographics, Clinical Features, Risk Factors, Microbiological Results, and Treatment. Cornea 2011, 30, 995-1002. [CrossRef]

31. Palmer, M.L.; Hyndiuk, R.A. Contact Lens-Related Infectious Keratitis. Int. Ophthalmol. Clin. 1993, 33, $23-49$. [CrossRef]

32. Kerr, N.; Stern, G.A. Bacterial Keratitis Associated with Vernal Keratoconjunctivitis. Cornea 1992, 11, 355-359. [CrossRef] [PubMed]

33. Parkunan, S.M.; Callegan, M.C. The Pathogenesis of Bacterial Endophthalmitis. In Endophthalmitis; Durand, M.L., Ed.; Springer International Publishing: Cham, Switzerland, 2016; pp. 17-47. [CrossRef]

34. Hautala, N.; Koskela, M.; Hautala, T. Major Age Group-Specific Differences in Conjunctival Bacteria and Evolution of Antimicrobial Resistance Revealed by Laboratory Data Surveillance. Curr. Eye Res. 2008, 33, 907-911. [CrossRef] [PubMed]

35. McCormick, C.C.; Caballero, A.R.; Balzli, C.L.; Tang, A.; Weeks, A.; O'Callaghan, R.J. Diverse Virulence of Staphylococcus aureus Strains for the Conjunctiva. Curr. Eye Res. 2010, 36, 14-20. [CrossRef] [PubMed]

36. Tang, A.; Balzli, C.L.; Caballero, A.R.; McCormick, C.C.; Taylor, S.D.; O'Callaghan, R.J. Staphylococcus aureus Infection of the Rabbit Cornea Following Topical Administration. Curr. Eye Res. 2012, 37, 1075-1083. [CrossRef] [PubMed]

37. Zaidi, T.S.; Zaidi, T.; Pier, G.B. Antibodies to Conserved Surface Polysaccharides Protect Mice Against Bacterial Conjunctivitis. Investig. Opthalmol. Vis. Sci. 2018, 59, 2512-2519. [CrossRef]

38. Martin, M.; Turco, J.H.; Zegans, M.E.; Facklam, R.R.; Sodha, S.; Elliott, J.A.; Pryor, J.H.; Beall, B.; Erdman, D.D.; Baumgartner, Y.Y.; et al. An Outbreak of Conjunctivitis Due to Atypical Streptococcus pneumoniae. N. Engl. J. Med. 2003, 348, 1112-1121. [CrossRef]

39. Kim, J.H.; Kim, M.K.; Oh, J.Y.; Jang, K.C.; Wee, W.R.; Lee, J.H. Outbreak of Gram-Positive Bacterial Keratitis Associated with Epidemic Keratoconjunctivitis in Neonates and Infants. Eye 2009, 23, 1059-1065. [CrossRef]

40. Crum, N.F.; Barrozo, C.P.; Chapman, F.A.; Ryan, M.A.K.; Russell, K.L. An Outbreak of Conjunctivitis Due to a Novel Unencapsulated Streptococcus pneumoniae among Military Trainees. Clin. Infect. Dis. 2004, 39, 1148-1154. [CrossRef]

41. Buck, J.M.; Lexau, C.; Shapiro, M.; Glennen, A.; Boxrud, D.J.; Koziol, B.; Whitney, C.G.; Beall, B.; Danila, R.; Lynfield, R. A Community Outbreak of Conjunctivitis Caused by Nontypeable Streptococcus pneumoniae in Minnesota. Pediatr. Infect. Dis. J. 2006, 25, 906-911. [CrossRef]

42. Patel, P.B.; Diaz, M.C.G.; Bennett, J.E.; Attia, M.W. Clinical Features of Bacterial Conjunctivitis in Children. Acad. Emerg. Med. 2007, 14, 1-5. [CrossRef]

43. Shayegani, M.; Parsons, L.M.; Gibbons, W.E.; Campbell, D. Characterization of Nontypable Streptococcus Pneumoniae-like Organisms Isolated from Outbreaks of Conjunctivitis. J. Clin. Microbiol. 1982, 16, 8-14. [PubMed] 
44. Hyams, C.; Camberlein, E.; Cohen, J.M.; Bax, K.; Brown, J.S. The Streptococcus pneumoniae Capsule Inhibits Complement Activity and Neutrophil Phagocytosis by Multiple Mechanisms. Infect. Immun. 2010, 78, 704-715. [CrossRef] [PubMed]

45. Johnson, S.E.; Rubin, L.; Romero-Steiner, S.; Dykes, J.K.; Pais, L.B.; Rizvi, A.; Ades, E.; Carlone, G.M. Correlation of Opsonophagocytosis and Passive Protection Assays Using Human Anticapsular Antibodies in an Infant Mouse Model of Bacteremia for Streptococcus pneumoniae. J. Infect. Dis. 1999, 180, 133-140. [CrossRef] [PubMed]

46. Kadioglu, A.; Taylor, S.; Iannelli, F.; Pozzi, G.; Mitchell, T.J.; Andrew, P.W. Upper and Lower Respiratory Tract Infection by Streptococcus pneumoniae Is Affected by Pneumolysin Deficiency and Differences in Capsule Type. Infect. Immun. 2002, 70, 2886-2890. [CrossRef]

47. Norcross, E.W.; Tullos, N.A.; Taylor, S.D.; Sanders, M.E.; Marquart, M.E. Assessment of Streptococcus pneumoniae Capsule in Conjunctivitis and Keratitis in Vivo Neuraminidase Activity Increases in Nonencapsulated Pneumococci Following Conjunctival Infection. Curr. Eye Res. 2010, 35, 787-798. [CrossRef]

48. Johnson, M.K.; Boese-Marrazzo, D.; Pierce, W.A. Effects of Pneumolysin on Human Polymorphonuclear Leukocytes and Platelets. Infect. Immun. 1981, 34, 171-176.

49. Cockeran, R.; Theron, A.J.; Steel, H.C.; Matlola, N.M.; Mitchell, T.J.; Feldman, C.; Anderson, R. Proinflammatory Interactions of Pneumolysin with Human Neutrophils. J. Infect. Dis. 2001, 183, 604-611. [CrossRef]

50. Valentino, M.D.; McGuire, A.M.; Rosch, J.W.; Bispo, P.J.M.; Burnham, C.; Sanfilippo, C.M.; Carter, R.A.; Zegans, M.E.; Beall, B.; Earl, A.M.; et al. Unencapsulated Streptococcus pneumoniae from Conjunctivitis Encode Variant Traits and Belong to a Distinct Phylogenetic Cluster. Nat. Commun. 2014, 5, 1-12. [CrossRef]

51. Royle, L.; Matthews, E.; Corfield, A.; Berry, M.; Rudd, P.M.; Dwek, R.A.; Carrington, S.D. Glycan Structures of Ocular Surface Mucins in Man, Rabbit and Dog Display Species Differences. Glycoconj. J. 2008, 25, 763-773. [CrossRef]

52. Isnard, N.; Bourles-Dagonet, F.; Robert, L.; Renard, G. Studies on Corneal Wound Healing. Ophthalmologica 2005, 219, 324-333. [CrossRef]

53. Stocks, M.E.; Ogden, S.; Haddad, D.; Addiss, D.G.; Mcguire, C.; Freeman, M.C. Effect of Water, Sanitation, and Hygiene on the Prevention of Trachoma: A Systematic Review and Meta-Analysis. PLoS ONE 2014, 11, 1-29. [CrossRef]

54. Fitch, C.P.; Rapoza, P.A.; Owens, S.; Murillo-Lopez, F.; Johnson, R.A.; Quinn, T.C.; Pepose, J.S.; Taylor, H.R. Epidemiology and Diagnosis of Acute Conjunctivitis at an Inner-City Hospital. Ophthalmology 1989, 96, 1215-1220. [CrossRef]

55. Malaty, R.; Dawson, C.R.; Wong, I.; Lyon, C.; Schachter, J. Serum and Tear Antibodies to Chlamydia after Reinfection with Guinea Pig Inclusion Conjunctivitis Agent. Investig. Ophthalmol. Vis. Sci. 1981, 21, 833-841.

56. Rank, R.G.; Whittimore, J.; Bowlin, A.K.; Dessus-Babus, S.; Wyrick, P.B. Chlamydiae and Polymorphonuclear Leukocytes: Unlikely Allies in the Spread of Chlamydial Infection. FEMS Immunol. Med. Microbiol. 2008, 54, 104-113. [CrossRef]

57. Li, M.O.; Wan, Y.Y.; Sanjabi, S.; Robertson, A.-K.L.; Flavell, R.A. Transforming Growth Factor- $\beta$ Regulation of Immune Responses. Annu. Rev. Immunol. 2006, 24, 99-146. [CrossRef]

58. Veena, C. Bacteriological Study of Conjunctivitis. Int. J. Contemp. Med. Res. ISSN 2015, 3, 2393-2915.

59. Tarabishy, A.B.; Jeng, B.H. Bacterial Conjunctivitis: A Review for Internists. Clevel. Clin. J. Med. 2008, 75, 507-512. [CrossRef]

60. Wong, R.L.M.; Gangwani, R.A.; Yu, L.W.H.; Lai, J.S.M. New Treatments for Bacterial Keratitis. J. Ophthalmol. 2012, 2012, 1-7. [CrossRef]

61. Ansari, Z.; Miller, D.; Galor, A. Current Thoughts in Fungal Keratitis: Diagnosis and Treatment. Curr. Fungal Infect. Rep. 2013, 7, 209-218. [CrossRef]

62. Marquart, M.E.; O'Callaghan, R.J. Infectious Keratitis: Secreted Bacterial Proteins That Mediate Corneal Damage. J. Ophthalmol. 2013, 2013, 1-9. [CrossRef]

63. Hazlett, L.D.; Rosen, D.; Berk, R.S. Experimental Eye Infections Caused by Pseudomonas aeruginosa. Ophthalmic Res. 1976, 8, 311-318. [CrossRef]

64. Stapleton, F.; Carnt, N. Contact Lens-Related Microbial Keratitis: How Have Epidemiology and Genetics Helped Us with Pathogenesis and Prophylaxis. Eye 2011, 26, 185-193. [CrossRef] 
65. Musa, F.; Tailor, R.; Gao, A.; Hutley, E.; Rauz, S.; Scott, R.A.H.; Fayyaz, D.; Musa, U. Contact Lens-Related Microbial Keratitis in Deployed British Military Personnel Clinical Science. Br. J. Ophthalmol. 2010, 94, 988-993. [CrossRef]

66. Lin, A.; Rhee, M.K.; Akpek, E.K.; Amescua, G.; Farid, M.; Garcia-Ferrer, F.J.; Varu, D.M.; Musch, D.C.; Dunn, S.P.; Mah, F.S. Bacterial Keratitis Preferred Practice Pattern ${ }^{\circledR}$. Ophthalmology 2019, 126, P1-P55. [CrossRef]

67. Fleiszig, S.M.; Evans, D.J. Pathogenesis of contact lens-associated microbial keratitis. Optom. Vis. Sci. 2010, 87, 225-232. [CrossRef]

68. Evans, D.J.; McNamara, N.A.; Fleiszig, S.M. Life at the Front: Dissecting Bacterial-Host Interactions at the Ocular Surface. Ocul. Surf. 2007, 5, 213-227. [CrossRef]

69. Williamson, Y.M.; Gowrisankar, R.; Longo, D.L.; Facklam, R.; Gipson, I.K.; Ades, E.P.; Carlone, G.M.; Sampson, J.S. Adherence of Nontypeable Streptococcus pneumoniae to Human Conjunctival Epithelial Cells. Microb. Pathog. 2008, 44, 175-185. [CrossRef]

70. Rhem, M.N.; Lech, E.M.; Patti, J.M.; Mcdevitt, D.; Höök, M.; Höök, H.; Höök, H.; Jones, D.B.; Wilhelmus, K.R.; Richardson, S.W. The Collagen-Binding Adhesin Is a Virulence Factor in Staphylococcus aureus Keratitis. Infect. Immun. 2000, 68, 3776-3779. [CrossRef]

71. Astley, R.; Miller, F.C.; Mursalin, M.H.; Coburn, P.S.; Callegan, M.C. An Eye on Staphylococcus aureus toxins: Roles in Ocular Damage and Inflammation. Toxins 2019, 11, 356. [CrossRef]

72. Vareechon, C.; Zmina, S.E.; Karmakar, M.; Pearlman, E.; Rietsch, A. Pseudomonas Aeruginosa Effector ExoS Inhibits ROS Production in Human Neutrophils. Cell Host Microbe 2017, 21, 611-618.e5. [CrossRef]

73. Webeye.ophth.uiowa.edu. Available online: https://webeye.ophth.uiowa.edu/eyeforum/atlas/pages/ pseudomonas-keratitis-34.html (accessed on 28 October 2019).

74. Lee, K.; Lee, H.; Kim, M. Two Cases of Corneal Ulcer due to Methicillin-Resistant Staphylococcus aureus in High Risk Groups. Korean J. Ophthalmol. 2010, 24, 240-244. [CrossRef]

75. Alvarruiz-Picazo, J.; Blanco-Marchite, N.; Donate-Tercero, A.; Blanco-Marchite, C.I.; Bautista-Ruescas, V. Streptococcus pneumoniae keratitis, a case report. Arch. Med. 2009, 1, 1-4.

76. Gerke, J.R.; Magliocco, M.V. Experimental Pseudomonas aeruginosa Infection of the Mouse Cornea. Infect. Immun. 1971, 3, 209-216.

77. Chusid, M.J.; Davis, S.D. Experimental Bacterial Keratitis in Neutropenic Guinea Pigs: Polymorphonuclear Leukocytes in Corneal Host Defense. Infect. Immun. 1979, 24, 948-952.

78. Hazlett, L.D.; Rosen, D.; Berk, R.S. Pseudomonas Eye Infections in Cyclophosphamide-Treated Mice. Investig. Opthalmol. Vis. Sci. 1977, 16, 649-652.

79. Zaidi, T.S.; Zaidi, T.; Pier, G.B. Role of Neutrophils, MyD88-Mediated Neutrophil Recruitment, and Complement in Antibody-Mediated Defense against Pseudomonas aeruginosa Keratitis. Investig. Ophthalmol. Vis. Sci. 2010, 51, 2085-2093. [CrossRef]

80. Thanabalasuriar, A.; Scott, B.N.V.; Peiseler, M.; Willson, M.E.; Zeng, Z.; Warrener, P.; Keller, A.E.; Surewaard, B.G.J.; Dozier, E.A.; Korhonen, J.T.; et al. Neutrophil Extracellular Traps Confine Pseudomonas aeruginosa Ocular Biofilms and Restrict Brain Invasion. Cell Host Microbe 2019, 25, 526-536. [CrossRef]

81. Sun, Y.; Karmakar, M.; Taylor, P.R.; Rietsch, A.; Pearlman, E. ExoS and ExoT ADP Ribosyltransferase Activities Mediate Pseudomonas aeruginosa Keratitis by Promoting Neutrophil Apoptosis and Bacterial Survival. J. Immunol. 2012, 188, 1884-1895. [CrossRef]

82. Zhang, J.; Xu, K.; Ambati, B.; Yu, F.S.X. Toll-like Receptor 5-Mediated Corneal Epithelial Inflammatory Responses to Pseudomonas aeruginosa Flagellin. Investig. Ophthalmol. Vis. Sci. 2003, 44, 4247-4254. [CrossRef]

83. Karmakar, M.; Sun, Y.; Hise, A.G.; Rietsch, A.; Pearlman, E. IL-1 $\beta$ Processing during Pseudomonas aeruginosa Infection Is Mediated by Neutrophil Serine Proteases and Is Independent of NLRC4 and Caspase-1. J. Immunol. 2012, 189, 4231-4235. [CrossRef]

84. Xue, M.-L.; Thakur, A.; Cole, N.; Lloyd, A.; Stapleton, F.; Wakefield, D.; Willcox, M.D.P. A Critical Role for CCL2 and CCL3 Chemokines in the Regulation of Polymorphonuclear Neutrophils Recruitment during Corneal Infection in Mice. Immunol. Cell Biol. 2007, 85, 525-531. [CrossRef]

85. Jeng, B.H.; Gritz, D.C.; Kumar, A.B.; Holsclaw, D.S.; Porco, T.C.; Smith, S.D.; Whitcher, J.P.; Margolis, T.P.; Wong, I.G. Epidemiology of Ulcerative Keratitis in Northern California. Arch. Ophthalmol. 2010, 128, 1022-1028. [CrossRef] 
86. Shanmuganathan, V.A.; Armstrong, M.; Buller, A.; Tullo, A.B. External Ocular Infections Due to Methicillin-Resistant Staphylococcus aureus (MRSA). Eye 2005, 19, 284-291. [CrossRef]

87. Solomon, R.; Donnenfeld, E.D.; Perry, H.D.; Biser, S. Bilateral Methicillin-Resistant Staphylococcus aureus Keratitis in a Medical Resident Following an Uneventful Bilateral Photorefractive Keratectomy. Eye Contact Lens 2003, 29, 187-189. [CrossRef]

88. Callegan, M.C.; Engel, L.S.; Hill, J.M.; O'Callaghan, R.J. Corneal Virulence of Staphylococcus aureus: Roles of Alpha-Toxin and Protein A in Pathogenesis. Infect. Immun. 1994, 62, 2478-2482.

89. Sloop, G.D.; Moreau, J.M.; Conerly, L.L.; Dajcs, J.J.; O'Callaghan, R.J. Acute Inflammation of the Eyelid and Cornea in Staphylococcus Keratitis in the Rabbit. Investig. Ophthalmol. Vis. Sci. 1999, 40, 385-391.

90. Chusid, M.J.; Nelson, D.B.; Meyer, L.A. The Role of the Polymorphonuclear Leukocyte in the Induction of Corneal Edema. Investig. Ophthalmol. Vis. Sci. 1986, 27, 1466-1469.

91. O'Callaghan, R.J.; Callegan, M.C.; Moreau, J.M.; Green, L.C.; Foster, T.J.; Hartford, O.M.; Engel, L.S.; Hill, J.M. Specific Roles of Alpha-Toxin and Beta-Toxin during Staphylococcus Aureus Corneal Infection. Infect. Immun. 1997, 65, 1571-1578.

92. O'Callaghan, R.J.; Girgis, D.O.; Dajcs, J.J.; Sloop, G.D. Host Defense against Bacterial Keratitis. Ocul. Immunol. Inflamm. 2003, 11, 171-181. [CrossRef]

93. Kumar, A.; Zhang, J.; Yu, F.-S.X. Innate Immune Response of Corneal Epithelial Cells to Staphylococcus aureus Infection: Role of Peptidoglycan in Stimulating Proinflammatory Cytokine Secretion. Investig. Ophthalmol. Vis. Sci. 2004, 45, 3513-3522. [CrossRef]

94. Sun, Y.; Hise, A.G.; Kalsow, C.M.; Pearlman, E. Staphylococcus aureus-Induced Corneal Inflammation Is Dependent on Toll-Like Receptor 2 and Myeloid Differentiation Factor 88. Infect. Immun. 2006, 74, 5325-5332. [CrossRef] [PubMed]

95. Cole, N.; Hume, E.B.H.; Khan, S.; Garthwaite, L.; Conibear, T.C.R.; Willcox, M.D.P. The Role of CXC Chemokine Receptor 2 in Staphylococcus aureus Keratitis. Exp. Eye Res. 2014, 12 7, 184-189. [CrossRef]

96. Khan, S.; Cole, N.; Hume, E.B.; Garthwaite, L.; Conibear, T.C.R.; Miles, D.H.; Aliwaga, Y.; Krockenberger, M.B.; Willcox, M.D.P. The Role of CXC Chemokine Receptor 2 in Pseudomonas aeruginosa Corneal Infection. J. Leukoc. Biol. 2007, 81, 315-318. [CrossRef] [PubMed]

97. Heimer, S.R.; Evans, D.J.; Mun, J.J.; Stern, M.E.; Fleiszig, S.M. Surfactant protein D contributes to ocular defense against Pseudomonas aeruginosa in a murine model of dry eye disease. PLoS ONE 2013, 8, e65797. [CrossRef] [PubMed]

98. Mun, J.J.; Tam, C.; Kowbel, D.; Hawgood, S.; Barnett, M.J.; Evans, D.J.; Fleiszig, S.M. Clearance of Pseudomonas aeruginosa from a healthy ocular surface involves surfactant protein $\mathrm{D}$ and is compromised by bacterial elastase in a murine null-infection model. Infect. Immun. 2009, 77, 2392-2398. [CrossRef] [PubMed]

99. Zhang, Z.; Abdel-Razek, O.; Hawgood, S.; Wang, G. Protective Role of Surfactant Protein D in Ocular Staphylococcus aureus Infection. PLoS ONE 2015, 10, 1-17. [CrossRef] [PubMed]

100. Booth, M.C.; Pence, L.M.; Mahasreshti, P.; Callegan, M.C.; Gilmore, M.S. Clonal associations among Staphylococcus aureus isolates from various sites of infection. Infect. Immun. 2001, 69, 345-353. [CrossRef] [PubMed]

101. Coia, J.E.; Browning, L.; Haines, L.; Birkbeck, T.H.; Platt, D.J. Comparison of Enterotoxins and Haemolysins Produced by Methicillin-Resistant (MRSA) and Sensitive (MSSA) Staphylococcus aureus. J. Med. Microbiol. 1992, 36, 164-171. [CrossRef]

102. Kwak, Y.K.; Vikstrom, E.; Magnusson, K.E.; Vecsey-Semjen, B.; Colque-Navarro, P.; Mollby, R. The Staphylococcus aureus alpha-toxin perturbs the barrier function in Caco-2 epithelial cell monolayers by altering junctional integrity. Infect. Immun. 2012, 80, 1670-1680. [CrossRef]

103. Hocke, A.C.; Temmesfeld-Wollbrueck, B.; Schmeck, B.; Berger, K.; Frisch, E.M.; Witzenrath, M.; Brell, B.; Suttorp, N.; Hippenstiel, S. Perturbation of endothelial junction proteins by Staphylococcus aureus alpha-toxin: Inhibition of endothelial gap formation by adrenomullin. Histochem. Cell Biol. 2006, 126, 305-316. [CrossRef]

104. Dajcs, J.J.; Thibodeaux, B.A.; Girgis, D.O.; O'Callaghan, R.J. Corneal Virulence of Staphylococcus aureus in an Experimental Model of Keratits. DNA Cell Biol. 2004, 21, 375-382. [CrossRef] [PubMed]

105. Kumar, A.; Tassopoulos, A.M.; Li, Q.; Yu, F.-S.X. Staphylococcus aureus Protein A Induced Inflammatory Response in Human Corneal Epithelial Cells. Biochem. Biophys. Res. Commun. 2007, 354, 955-961. [CrossRef] 
106. Bharathi, M.J.; Ramakrishnan, R.; Shivakumar, C.; Meenakshi, R.; Lionalraj, D. Etiology and Antibacterial Susceptibility Pattern of Community-Acquired Bacterial Ocular Infections in a Tertiary Eye Care Hospital in South India. Indian J. Ophthalmol. 2010, 58, 497-507. [CrossRef] [PubMed]

107. Yilmaz, S.; Ozturk, I.; Maden, A. Microbial Keratitis in West Anatolia, Turkey: A Retrospective Review. Int. Ophthalmol. 2007, 27, 261-268. [CrossRef] [PubMed]

108. Parmar, P.; Salman, A.; Kalavathy, C.M.; Jesudasan, C.A.N.; Thomas, P.A. Pneumococcal Keratitis: A Clinical Profile. Clin. Exp. Ophthalmol. 2003, 31, 44-47. [CrossRef] [PubMed]

109. Gosbell, I.B.; Neville, S.A. Antimicrobial Resistance in Streptococcus pneumoniae: A Decade of Results from South-Western Sydney. Commun. Dis. Intell. 2000, 24, 340-343.

110. Lu, C.Y.; Lee, P.I.; Hsueh, P.R.; Chang, S.C.; Chiu, T.F.; Lin, H.C.; Lee, C.Y.; Huang, L.M. Penicillin-Nonsusceptible Streptococcus pneumoniae Infections in Children. J. Microbiol. Immunol. Infect. 1999, 32, 179-186.

111. Cosar, C.B.; Cohen, E.J.; Rapuano, C.J.; Laibson, P.R. Clear Corneal Wound Infection After Phacoemulsification. Arch. Ophthalmol. 2001, 119, 1755-1759. [CrossRef]

112. Mulet, M.E.; Pérez-Santonja, J.J.; Ferrer, C.; Alió, J.L. Microbial Keratitis After Intrastromal Corneal Ring Segment Implantation. J. Refract. Surg. 2010, 26, 364-369. [CrossRef]

113. Rehany, U.; Balut, G.; Lefler, E.; Rumelt, S. The Prevalence and Risk Factors for Donor Corneal Button Contamination and Its Association with Ocular Infection after Transplantation. Cornea 2004, 23, 649-654. [CrossRef]

114. Okonkwo, A.C.O.; Siah, W.F.; Hogg, H.D.J.; Anwar, H.; Figueiredo, F.C. Microbial Keratitis in Corneal Grafts: Predisposing Factors and Outcomes. Eye 2018, 32, 775-781. [CrossRef] [PubMed]

115. Johnson, M.K.; Hobden, J.A.; Hagenah, M.; O'Callaghan, R.J.; Hill, J.M.; Chen, S. The Role of Pneumolysin in Ocular Infections with Streptococcus pneumoniae. Curr. Eye Res. 1990, 9, 1107-1114. [CrossRef] [PubMed]

116. Harrison, J.C.; Karcioglu, Z.A.; Johnson, M.K. Response of Leukopenic Rabbits to Pneumococcal Toxin. Curr. Eye Res. 1982, 2, 705-710. [CrossRef] [PubMed]

117. Norcross, E.W.; Sanders, M.E.; Moore, Q.C.; Marquart, M.E.; Marquart, M.E. Pathogenesis of A Clinical Ocular Strain of Streptococcus pneumoniae and the Interaction of Pneumolysin with Corneal Cells. J. Bacteriol. Parasitol. 2011, 2, 1-16. [CrossRef] [PubMed]

118. Johnson, M.K.; Allen, J.H. The Role of Cytolysin in Pneumococcal Ocular Infection. Am. J. Ophthalmol. 1975, 80, 518-521. [CrossRef]

119. Johnson, M.K.; Callegan, M.C.; Engel, L.S.; O'Callaghan, R.J.; Hill, J.M.; Hobden, J.A.; Boulnois, G.J.; Andrew, P.W.; Mitchell, T.J. Growth andv virulence of a complement-activation-negative mutant of Streptococcus pneumonia in the rabbit cornea. Curr. Eye Res. 1995, 14, 281-284. [CrossRef]

120. Karmakar, M.; Katsnelson, M.; Malak, H.A.; Greene, N.G.; Howell, S.J.; Hise, A.G.; Camilli, A.; Kadioglu, A.; Dubyak, G.R.; Pearlman, E. Neutrophil IL-1 $\beta$ Processing Induced by Pneumolysin Is Mediated by the NLRP3/ASC Inflammasome and Caspase-1 Activation, and Is Dependent on K + Efflux. J. Immunol. 2015, 194, 1763-1775. [CrossRef]

121. Jedrzejas, M.J. Pneumococcal Virulence Factors: Structure and Function. Microbiol. Mol. Biol. Rev. 2001, 65, 187-207. [CrossRef]

122. Srinivasan, M.; Gonzales, C.A.; George, C.; Cevallos, V.; Mascarenhas, J.M.; Asokan, B.; Wilkins, J.; Smolin, G.; Whitcher, J.P. Epidemiology and Aetiological Diagnosis of Corneal Ulceration in Madurai, South India. Br. J. Ophthalmol. 1997, 81, 965-971. [CrossRef]

123. Norina, T.J.; Raihan, S.; Bakiah, S.; Ezanee, M.; Liza-Sharmini, A.T.; Wan Hazzabah, W.H. Microbial Keratitis: Aetiological Diagnosis and Clinical Features in Patients Admitted to Hospital Universiti Sains Malaysia. Singap. Med. J. 2008, 49, 67-71.

124. Bharathi, M.J.; Ramakrishnan, R.; Vasu, S.; Meenakshi, R.; Shivkumar, C.; Palaniappan, R. Epidemiology of Bacterial Keratitis in a Referral Centre in South India. Indian J. Med. Microbiol. 2003, 21, 239-245. [PubMed]

125. Reed, J.M.; O'Callaghan, R.J.; Girgis, D.O.; McCormick, C.C.; Caballero, A.R.; Marquart, M.E. Ocular Virulence of Capsule-Deficient Streptococcus pneumoniae in a Rabbit Keratitis Model. Investig. Ophthalmol. Vis. Sci. 2005, 46, 604-608. [CrossRef] [PubMed]

126. Jones, D.B. Decision-Making in the Management of Microbial Keratitis. Ophthalmology 1981, 88, 814-820. [CrossRef] 
127. Solanki, S.; Rathi, M.; Khanduja, S.; Dhull, C.S.; Sachdeva, S.; Phogat, J. Recent Trends: Medical Management of Infectious Keratitis. Oman J. Ophthalmol. 2015, 8, 83-85. [CrossRef]

128. Rathinam, S.; Namperumalsamy, P. Global Variation and Pattern Changes in Epidemiology of Uveitis. Indian J. Ophthalmol. 2007, 55, 173-183. [CrossRef]

129. Suhler, E.B.; Lloyd, M.J.; Choi, D.; Rosenbaum, J.T.; Austin, D.F. Incidence and Prevalence of Uveitis in Veterans Affairs Medical Centers of the Pacific Northwest. Am. J. Ophthalmol. 2008, 146, 890-896.e8. [CrossRef]

130. Lin, P. Infectious Uveitis. Curr. Ophthalmol. Rep. 2015, 3, 170-183. [CrossRef]

131. Aldave, A.J.; King, J.A.; Cunningham, E.T. Ocular Syphilis. Curr. Opin. Ophthalmol. 2001, 12, $433-441$. [CrossRef]

132. Bernard, A.; Kodjikian, L.; Abukhashabh, A.; Roure-Sobas, C.; Boibieux, A.; Denis, P.; Broussolle, C.; Seve, P. Diagnosis of Lyme-associated Uveitis: Value of Serological Testing in a Tertiary Centre. Br. J. Ophthalmol. 2018, 102, 369-372. [CrossRef]

133. Bernard, A.; Seve, P.; Abukhashabh, A.; Roure-Sobas, C.; Boibieux, A.; Denis, P.; Broussolle, C.; Mathis, T.; Kodjikian, L. Lyme-Associated Uveitis: Clinical Spectrum and Review of Literature. Eur. J. Ophthalmol. 2019. [CrossRef]

134. Singh, R.; Gupta, V.; Gupta, A. Pattern of Uveitis in a Referral Eye Clinic in North India. Indian J. Ophthalmol. 2004, 52, 121-125. [PubMed]

135. Kaimbo Wa Kimbo, D.; Bifuko, A.; Dernouchamps, J.P.; Missotten, L. Chronic Uveitis in Kinshasa (D R Congo). Bull. Soc. Belge Ophtalmol. 1998, 270, 95-100. [PubMed]

136. Ayo, C. A Toxic Ocular Reaction I. New Property of Shwartzman Toxins. J. Immunol. 1943, 46, 113-132.

137. Whitcup, S.M.; Wakefield, D.; Li, Q.; Nussenblatt, R.B.; Chan, C.C. Endothelial Leukocyte Adhesion Molecule-1 in Endotoxin-Induced Uveitis. Investig. Ophthalmol. Vis. Sci. 1992, 33, 2626-2630.

138. Whitcup, S.M.; DeBarge, L.R.; Rosen, H.; Nussenblatt, R.B.; Chan, C.C. Monoclonal Antibody against CD11b/CD18 Inhibits Endotoxin-Induced Uveitis. Investig. Ophthalmol. Vis. Sci. 1993, 34, 673-681.

139. Li, X.; Gu, X.; Boyce, T.M.; Zheng, M.; Reagan, A.M.; Qi, H.; Mandal, N.; Cohen, A.W.; Callegan, M.C.; Carr, D.J.J.; et al. Caveolin-1 Increases Proinflammatory Chemoattractants and Blood-Retinal Barrier Breakdown but Decreases Leukocyte Recruitment in Inflammation. Investig. Ophthalmol. Vis. Sci. 2014, 55, 6224-6234. [CrossRef]

140. Hoekzema, R.; Murray, P.I.; van Haren, M.A.; Helle, M.; Kijlstra, A. Analysis of Interleukin-6 in Endotoxin-Induced Uveitis. Investig. Ophthalmol. Vis. Sci. 1991, 32, 88-95.

141. Granowitz, E.V.; Poutsiaka, D.D.; Cannon, J.G.; Wolff, S.M.; Dinarello, C.A.; Santos, A.A.; Wilmore, D.W. Production of Interleukin-1-Receptor Antagonist during Experimental Endotoxaemia. Lancet 1991, 338, 1423-1424. [CrossRef]

142. Okumura, A.; Mochizuki, M.; Nishi, M.; Herbort, C.P. Endotoxin-Induced Uveitis (EIU) in the Rat: A Study of Inflammatory and Immunological Mechanisms. Int. Ophthalmol. 1989, 14, 31-36. [CrossRef]

143. Rosenbaum, J.T.; McDevitt, H.O.; Guss, R.B.; Egbert, P.R. Endotoxin-Induced Uveitis in Rats as a Model for Human Disease. Nature 1980, 286, 611-613. [CrossRef]

144. Howes, E.L.; Goldyne, M.E.; Perez, H.D.; Goldstein, I.M.; Rosenbaum, J.T. Lipopolysaccharide Tolerance Inhibits Eye Inflammation. Arch. Ophthalmol. 1985, 103, 261-265. [CrossRef] [PubMed]

145. Bhattacherjee, P.; Parke, A. The Reduction of Inflammatory Responses in Lipopolysaccharide-Tolerant Eyes. Am. J. Pathol. 1986, 122, 268-276. [PubMed]

146. Chang, J.H.; Hampartzoumian, T.; Everett, B.; Lloyd, A.; McCluskey, P.J.; Wakefield, D. Changes in Toll-like Receptor (TLR)-2 and TLR4 Expression and Function but Not Polymorphisms Are Associated with Acute Anterior Uveitis. Investig. Opthalmol. Vis. Sci. 2007, 48, 1711-1717. [CrossRef] [PubMed]

147. Mashimo, H.; Ohguro, N.; Nomura, S.; Hashida, N.; Nakai, K.; Tano, Y. Neutrophil Chemotaxis and Local Expression of Interleukin-10 in the Tolerance of Endotoxin-Induced Uveitis. Investig. Opthalmol. Vis. Sci. 2008, 49, 5450-5457. [CrossRef]

148. Callegan, M.C.; Engelbert, M.; Ii, D.W.P.; Jett, B.D.; Gilmore, M.S. Bacterial Endophthalmitis: Epidemiology, Therapeutics, and Bacterium-Host Interactions. Clin. Microbiol. Rev. 2002, 15, 111-124. [CrossRef]

149. Callegan, M.C.; Gilmore, M.S.; Gregory, M.; Ramadan, R.T.; Wiskur, B.J.; Moyer, A.L.; Hunt, J.J.; Novosad, B.D. Bacterial Endophthalmitis: Therapeutic Challenges and Host-Pathogen Interactions. Prog. Retin. Eye Res. 2007, 26, 189-203. [CrossRef] 
150. Bhagat, N.; Nagori, S.; Zarbin, M. Post-Traumatic Infectious Endophthalmitis. Surv. Ophthalmol. 2011, 56, 214-251. [CrossRef]

151. Kattan, H.M.; Flynn, H.W.; Pflugfelder, S.C.; Robertson, C.; Forster, R.K. Nosocomial Endophthalmitis Survey. Current Incidence of Infection after Intraocular Surgery. Ophthalmology 1991, 98, 227-238. [CrossRef]

152. Vision 2020. The Right to Sight. Global Initiative for the Elimination of Avoidable Blindness. Available online: https://www.who.int/blindness/Vision2020_report.pdf (accessed on 25 June 2019).

153. Kresloff, M.S.; Castellarin, A.A.; Zarbin, M.A. Endophthalmitis. Surv. Ophthalmol. 1998, 43, $193-224$. [CrossRef]

154. Kernt, M.; Kampik, A.; Kernt, M. Clinical Ophthalmology Endophthalmitis: Pathogenesis, Clinical Presentation, Management, and Perspectives. Clin. Ophthalmol. 2010, 4, 121-135. [CrossRef]

155. Results of the Endophthalmitis Vitrectomy Study. A Randomized Trial of Immediate Vitrectomy and of Intravenous Antibiotics for the Treatment of Postoperative Bacterial Endophthalmitis. Endophthalmitis Vitrectomy Study Group. Arch. Ophthalmol. 1995, 113, 1479-1496. [CrossRef]

156. Seal, D.; Reischl, U.; Behr, A.; Ferrer, C.; Alió, J.; Koerner, R.J.; Barry, P.; ESCRS Endophthalmitis Study Group. Laboratory Diagnosis of Endophthalmitis: Comparison of Microbiology and Molecular Methods in the European Society of Cataract; Refractive Surgeons Multicenter Study and Susceptibility Testing. J. Cataract Refract. Surg. 2008, 34, 1439-1450. [CrossRef] [PubMed]

157. Scott, I.U.; Flynn, H.W.; Feuer, W.; Pflugfelder, S.C.; Alfonso, E.C.; Forster, R.K.; Miller, D. Endophthalmitis Associated with Microbial Keratitis. Ophthalmology 1996, 103, 1864-1870. [CrossRef]

158. Maitray, A.; Rishi, E.; Rishi, P.; Gopal, L.; Bhende, P.; Ray, R.; Therese, K.L. Endogenous endophthalmitis in children and adolescents: Case series and literature review. Indian J. Ophthalmol. 2019, 67, 795-800. [PubMed]

159. Pan, Q.; Liu, Y.; Wang, R.; Chen, T.; Yang, Z.; Deng, Y.; Zhao, Z.; Hu, X.; Chen, X.; Wei, W.; et al. Treatment of Bacillus cereus endophthalmitis with endoscopy-assisted vitrectomy. Medicine 2017, 50, 1-6. [CrossRef]

160. Ahn, M.W.; Shin, M.K.; Park, S.W.; Lee, J.E. Two Cases of Recurrent Enterococcus Faecalis Endophthalmitis after Cataract Surgery. J. Korean Ophthalmol. Soc. 2015, 4, 632-637. [CrossRef]

161. Callegan, M.C.; Booth, M.C.; Jett, B.D.; Gilmore, M.S. Pathogenesis of Gram-Positive Bacterial Endophthalmitis. Infect. Immun. 1999, 67, 3348-3356.

162. Callegan, M.C.; Cochran, D.C.; Kane, S.T.; Gilmore, M.S.; Gominet, M.; Lereclus, D. Contribution of Membrane-Damaging Toxins to Bacillus Endophthalmitis Pathogenesis. Infect. Immun. 2002, 70, 5381-5389. [CrossRef]

163. Callegan, M.C.; Kane, S.T.; Cochran, D.C.; Gilmore, M.S. Bacteria Molecular Mechanisms of Bacillus Endophthalmitis Pathogenesis. DNA Cell Biol. 2004, 21, 367-373. [CrossRef]

164. Giese, M.J.; Berliner, J.A.; Riesner, A.; Wagar, E.A.; Mondino, B.J. A Comparison of the Early Inflammatory Effects of an Agr-/Sar-versus a Wild Type Strain of Staphylococcus aureus in a Rat Model of Endophthalmitis. Curr. Eye Res. 1999, 18, 177-185. [CrossRef]

165. Weiss, S.J. Tissue Destruction by Neutrophils. N. Engl. J. Med. 1989, 320, 365-376. [CrossRef] [PubMed]

166. Affeldt, J.C.; Flynn, H.W.; Forster, R.K.; Mandelbaum, S.; Clarkson, J.G.; Jarus, G.D. Microbial Endophthalmitis Resulting from Ocular Trauma. Ophthalmology 1987, 94, 407-413. [CrossRef]

167. Olson, J.C.; Flynn, H.W.; Forster, R.K.; Culbertson, W.W. Results in the Treatment of Postoperative Endophthalmitis. Ophthalmology 1983, 90, 692-699. [CrossRef]

168. Rowsey, J.J.; Newsom, D.L.; Sexton, D.J.; Harms, W.K. Endophthalmitis: Current Approaches. Ophthalmology 1982, 89, 1055-1066. [CrossRef]

169. Major, J.C.; Engelbert, M.; Flynn, H.W.; Miller, D.; Smiddy, W.E.; Davis, J.L. Staphylococcus aureus Endophthalmitis: Antibiotic Susceptibilities, Methicillin Resistance, and Clinical Outcomes. Am. J. Ophthalmol. 2010, 149, 278-283. [CrossRef]

170. Abbey, M.A.; Darlene, M.; Flynn, H.W. Staphylococcus aureus Endophthalmitis: Antibiotic Susceptibilities, Methicillin Resistance, and Clinical Outcomes. Investig. Ophthalmol. Vis. Sci. 2012, 53, 1689.

171. Suzuki, T.; Campbell, J.; Swoboda, J.G.; Walker, S.; Gilmore, M.S. Role of wall teichoic acids in Staphylococcus aureus endophthalmitis. Investig. Ophthalmol. Vis. Sci. 2011, 52, 3187-3192. [CrossRef]

172. Kumar, A.; Kumar, A. Role of Staphylococcus aureus Virulence Factors in Inducing Inflammation and Vascular Permeability in a Mouse Model of Bacterial Endophthalmitis. PLoS ONE 2015, 10, 1-17. [CrossRef] 
173. Siqueira, J.A.; Speeg-Schatz, C.; Freitas, F.I.S.; Sahel, J.; Monteil, H.; Prevost, G. Channel-Forming Leucotoxins from Staphylococcus aureus Cause Severe Inflammatory Reactions in a Rabbit Eye Model. J. Med. Microbiol. 1997, 46, 486-494. [CrossRef]

174. Jenul, C.; Horswill, A.R. Regulation of Staphylococcus aureus Virulence. Microbiol. Spectr. 2018, 6, 1-34. [CrossRef]

175. Booth, M.C.; Atkuri, R.V.; Nanda, S.K.; Iandolo, J.J.; Gilmore, M.S. Accessory Gene Regulator Controls Staphylococcus aureus Virulence in Endophthalmitis. Infect. Immun. 1995, 36, 1828-1836.

176. Booth, M.C.; Cheung, A.L.; Hatter, K.L.; Jett, B.D.; Callegan, M.C.; Gilmore, M.S. Staphylococcal Accessory Regulator (Sar) in Conjunction with Agr Contributes to Staphylococcus aureus Virulence in Endophthalmitis. Infect. Immun. 1997, 65, 1550-1556. [PubMed]

177. Bhakdi, S.; Tranum-Jensen, J. Alpha-Toxin of Staphylococcus aureus. Microbiol. Rev. 1991, 55, $733-751$. [PubMed]

178. Giese, M.J.; Rayner, S.A.; Fardin, B.; Sumner, H.L.; Rozengurt, N.; Mondino, B.J.; Gordon, L.K. Mitigation of Neutrophil Infiltration in a Rat Model of Early Staphylococcus aureus Endophthalmitis. Investig. Ophthalmol. Vis. Sci. 2003, 44, 3077-3082. [CrossRef]

179. Rajamani, D.; Singh, P.K.; Rottmann, B.G.; Singh, N.; Bhasin, M.K.; Kumar, A. Temporal Retinal Transcriptome and Systems Biology Analysis Identifies Key Pathways and Hub Genes in Staphylococcus aureus Endophthalmitis. Sci. Rep. 2016, 6, 1-15. [CrossRef]

180. Kumar, A.; Giri, S.; Kumar, A. 5-Aminoimidazole-4-Carboxamide Ribonucleosidemediated Adenosine Monophosphate-Activated Protein Kinase Activation Induces Protective Innate Responses in Bacterial Endophthalmitis. Cell. Microbiol. 2016, 18, 1815-1830. [CrossRef]

181. Cho, J.S.; Pietras, E.M.; Garcia, N.C.; Ramos, R.I.; Farzam, D.M.; Monroe, H.R.; Magorien, J.E.; Blauvelt, A.; Kolls, J.K.; Cheung, A.L.; et al. IL-17 Is Essential for Host Defense against Cutaneous Staphylococcus aureus Infection in Mice. J. Clin. Investig. 2010, 120, 1762-1773. [CrossRef]

182. Minegishi, Y.; Saito, M.; Nagasawa, M.; Takada, H.; Hara, T.; Tsuchiya, S.; Agematsu, K.; Yamada, M.; Kawamura, N.; Ariga, T.; et al. Molecular Explanation for the Contradiction between Systemic Th17 Defect and Localized Bacterial Infection in Hyper-IgE Syndrome. J. Exp. Med. 2009, 206, 1291-1301. [CrossRef]

183. Karthikeyan, R.S.; Vareechon, C.; Prajna, N.V.; Dharmalingam, K.; Pearlman, E.; Lalitha, P. Interleukin 17 Expression in Peripheral Blood Neutrophils from Fungal Keratitis Patients and Healthy Cohorts in Southern India. J. Infect. Dis. 2015, 211, 130-134. [CrossRef]

184. Taylor, P.R.; Roy, S.; Leal, S.M.; Sun, Y.; Howell, S.J.; Cobb, B.A.; Li, X.; Pearlman, E. Activation of Neutrophils by Autocrine IL-17A-IL-17RC Interactions during Fungal Infection Is Regulated by IL-6, IL-23, ROR $\gamma \mathrm{t}$ and Dectin-2. Nat. Immunol. 2014, 15, 143-151. [CrossRef]

185. Miller, J.J.; Scott, I.U.; Flynn, H.W.; Smiddy, W.E.; Corey, R.P.; Miller, D. Endophthalmitis Caused by Streptococcus pneumoniae. Am. J. Ophthalmol. 2004, 138, 231-236. [CrossRef] [PubMed]

186. Mao, L.K.; Flynn, H.W.; Miller, D.; Pflugfelder, S.C. Endophthalmitis Caused by Streptococcal Species. Arch. Ophthalmol. 1992, 110, 798-801. [CrossRef] [PubMed]

187. Nouri, M.; Terada, H.; Alfonso, E.C.; Foster, C.S.; Durand, M.L.; Dohlman, C.H. Endophthalmitis After Keratoprosthesis. Arch. Ophthalmol. 2001, 119, 484-489. [CrossRef] [PubMed]

188. Soriano, F.; Pérez-Trallero, E.; Pallarés, R.; Meseguer, M.A.; Fleites, A.; Gené, A.; González, A.; Liñares, J.; Esteban, J.; Baquero, F.; et al. Streptococcus pneumoniae Endophthalmitis: A Study of 36 Cases with Special Reference to Antibiotic Resistance and Treatment Options. Clin. Microbiol. Infect. 2006, 12, 519-526. [CrossRef] [PubMed]

189. Mandelbaum, S.; Forster, R.K.; Gelender, H.; Culbertson, W. Late Onset Endophthalmitis Associated with Filtering Blebs. Ophthalmology 1985, 92, 964-972. [CrossRef]

190. Katz, L.J.; Cantor, L.B.; Spaeth, G.L. Complications of Surgery in Glaucoma. Early and Late Bacterial Endophthalmitis Following Glaucoma Filtering Surgery. Ophthalmology 1985, 92, 959-963. [CrossRef]

191. McCannel, C.A. Meta-analysis of Endophthalmitis After Intravitreal Injection of Anti-vascular Endothelial Growth Factor Agents. Retina 2011, 31, 654-661. [CrossRef]

192. Sanders, M.E.; Norcross, E.W.; Moore, Q.C.; Onwubiko, C.; King, L.B.; Fratkin, J.; Marquart, M.E.; Marquart, M.E. A Comparison of Pneumolysin Activity and Concentration in Vitro and in Vivo in a Rabbit Endophthalmitis Model. Clin. Ophthalmol. 2008, 2, 793-800. [CrossRef] 
193. Sanders, M.E.; Norcross, E.W.; Robertson, Z.M.; Moore, Q.C.; Fratkin, J.; Marquart, M.E. The Streptococcus pneumoniae Capsule Is Required for Full Virulence in Pneumococcal Endophthalmitis. Investig. Ophthalmol. Vis. Sci. 2011, 52, 865-872. [CrossRef]

194. Llull, D.; López, R.; García, E. Genetic Bases and Medical Relevance of Capsular Polysaccharide Biosynthesis in Pathogenic Streptococci. Curr. Mol. Med. 2001, 1, 475-491. [CrossRef]

195. Sanders, M.E.; Norcross, E.W.; Moore, Q.C.; Fratkin, J.; Thompson, H.; Marquart, M.E. Immunization with Pneumolysin Protects against Both Retinal and Global Damage Caused by Streptococcus pneumoniae Endophthalmitis. J. Ocul. Pharmacol. Ther. 2010, 26, 571-577. [CrossRef] [PubMed]

196. Ng, E.W.; Samiy, N.; Rubins, J.B.; Cousins, F.V.; Ruoff, K.L.; Baker, A.S.; D'Amico, D.J. Implication of Pneumolysin as a Virulence Factor in Streptococcus pneumoniae Endophthalmitis. Retina 1997, 17, 521-529. [CrossRef] [PubMed]

197. Ng, E.; Costa, J.R.; Samiy, N.; Ruoff, K.L.; Connolly, E.; Cousins, F.V.; D'Amico, D.J. Contribution of Pneumolysin and Autolysin to the Pathogenesis of Experimental Pneumococcal Endophthalmitis. Retina 2002, 22, 622-632. [CrossRef] [PubMed]

198. Benton, A.H.; Marquart, M.E. The Role of Pneumococcal Virulence Factors in Ocular Infectious Diseases. Interdiscip. Perspect. Infect. Dis. 2018, 2018,1-9. [CrossRef]

199. Sanders, M.E.; Taylor, S.; Tullos, N.; Norcross, E.W.; Moore, Q.C.; Thompson, H.; King, L.B.; Marquart, M.E. Passive Immunization with Pneumovax ${ }^{\circledR} 23$ and Pneumolysin in Combination with Vancomycin for Pneumococcal Endophthalmitis. BMC Ophthalmol. 2013, 13, 1-8. [CrossRef]

200. Tuomanen, E.; Liu, H.; Hengstler, B.; Zak, O.; Tomasz, A. The Induction of Meningeal Inflammation by Components of the Pneumococcal Cell Wall. J. Infect. Dis. 1985, 151, 859-868. [CrossRef]

201. Mitchell, T.J.; Alexander, J.E.; Morgan, P.J.; Andrew, P.W. Molecular Analysis of Virulence Factors of Streptococcus pneumoniae. J. Appl. Microbiol. 1997, 83, 62S-71S. [CrossRef]

202. Cowan, C.L.; Madden, W.M.; Hatem, G.F.; Merritt, J.C. Endogenous Bacillus cereus Panophthalmitis. Ann. Ophthalmol. 1987, 19, 65-68.

203. Davey, R.T.; Tauber, W.B. Posttraumatic Endophthalmitis: The Emerging Role of Bacillus cereus Infection. Rev. Infect. Dis. 1987, 9, 110-123. [CrossRef]

204. David, D.B.; Kirkby, G.R.; Noble, B.A. Bacillus cereus Endophthalmitis. Br. J. Ophthalmol. 1994, 78, 577-580. [CrossRef]

205. Callegan, M.C.; Cochran, D.C.; Kane, S.T.; Ramadan, R.T.; Chodosh, J.; McLean, C.; Stroman, D.W. Virulence Factor Profiles and Antimicrobial Susceptibilities of Ocular Bacillus Isolates. Curr. Eye Res. 2006, 31, 693-702. [CrossRef] [PubMed]

206. Bennouna, S.; Denkers, E.Y. Microbial Antigen Triggers Rapid Mobilization of TNF- $\alpha$ to the Surface of Mouse Neutrophils Transforming Them into Inducers of High-Level Dendritic Cell TNF- $\alpha$ Production. J. Immunol. 2005, 174, 4845-4851. [CrossRef] [PubMed]

207. Ramadan, R.T.; Moyer, A.L.; Callegan, M.C. A Role for Tumor Necrosis Factor- $\alpha$ in Experimental Bacillus cereus Endophthalmitis Pathogenesis. Investig. Ophthalmol. Vis. Sci. 2008, 49, 4482-4489. [CrossRef] [PubMed]

208. Parkunan, S.M.; Randall, C.B.; Astley, R.A.; Furtado, G.C.; Lira, S.A.; Callegan, M.C. CXCL1, but Not IL-6, Significantly Impacts Intraocular Inflammation during Infection. J. Leukoc. Biol. 2016, 100, 1125-1134. [CrossRef] [PubMed]

209. Novosad, B.D.; Astley, R.A.; Callegan, M.C. Role of Toll-like Receptor (TLR) 2 in Experimental Bacillus cereus Endophthalmitis. PLoS ONE 2011, 6, 1-7. [CrossRef] [PubMed]

210. Parkunan, S.M.; Randall, C.B.; Coburn, P.S.; Astley, R.A.; Staats, R.L.; Callegana, M.C. Unexpected Roles for Toll-like Receptor 4 and TRIF in Intraocular Infection with Gram-Positive Bacteria. Infect. Immun. 2015, 83, 3926-3936. [CrossRef] [PubMed]

211. Coburn, P.S.; Miller, F.C.; LaGrow, A.L.; Parkunan, S.M.; Blake Randall, C.; Staats, R.L.; Callegan, M.C. TLR4 Modulates Inflammatory Gene Targets in the Retina during Bacillus cereus Endophthalmitis. BMC Ophthalmol. 2018, 18, 1-11. [CrossRef]

212. Beecher, D.J.; Pulido, J.S.; Barney, N.P.; Lee Wong, A.C. Extracellular Virulence Factors in Bacillus cereus Endophthalmitis: Methods and Implication of Involvement of Hemolysin BL. Infect. Immun. 1995, 63, 632-639. [CrossRef] 
213. Callegan, M.C.; Jett, B.D.; Hancock, L.E.; Gilmore, M.S. Role of Hemolysin BL in the Pathogenesis of Extraintestinal Bacillus cereus Infection Assessed in an Endophthalmitis Model. Infect. Immun. 1999, 67, 3357-3366.

214. Beecher, D.J.; Olsen, T.W.; Somers, E.B.; Wong, A.C.L. Evidence for Contribution of Tripartite Hemolysin BL, Phosphatidylcholine-Preferring Phospholipase C, and Collagenase to Virulence of Bacillus cereus Endophthalmitis. Infect. Immun. 2000, 68, 5269-5276. [CrossRef]

215. Callegan, M.C.; Kane, S.T.; Cochran, D.C.; Gilmore, M.S.; Gominet, M.; Lereclus, D. Relationship of PlcR-Regulated Factors to Bacillus Endophthalmitis Virulence. Infect. Immun. 2003, 71, 3116-3124. [CrossRef] [PubMed]

216. Callegan, M.C.; Kane, S.T.; Cochran, D.C.; Novosad, B.; Gilmore, M.S.; Gominet, M.; Lereclus, D. Bacillus Endophthalmitis: Roles of Bacterial Toxins and Motility during Infection. Investig. Ophthalmol. Vis. Sci. 2005, 46, 3233-3238. [CrossRef] [PubMed]

217. Mursalin, M.H.; Coburn, P.S.; Livingston, E.; Miller, F.C.; Astley, R.; Fouet, A.; Callegan, M.C. S-Layer Impacts the Virulence of Bacillus in Endophthalmitis. Investig. Opthalmol. Vis. Sci. 2019, 60, 3727-3739. [CrossRef] [PubMed]

218. Gilmore, M.; Coburn, P.; Nallapareddy, S.; Murray, B. Enterococcal Virulence. In The Enterococci: Pathogenesis, Molecular Biology, and Antibiotic Resistance; Gilmore, C., Courvalin, D., Murray, R., Eds.; American Society of Microbiology: Washington, DC, USA, 2002; pp. 301-354. [CrossRef]

219. Antibiotic Resistance Threats in the United States. Available online: https://www.cdc.gov/drugresistance/ pdf/ar-threats-2013--508.pdf (accessed on 19 August 2019).

220. Stevens, S.X.; Jensen, H.G.; Jett, B.D.; Gilmore, M.S. A Hemolysin-Encoding Plasmid Contributes to Bacterial Virulence in Experimental Enterococcus Faecalis Endophthalmitis. Investig. Ophthalmol. Vis. Sci. 1992, 33, 1650-1656.

221. Jett, B.D.; Jensen, H.G.; Nordquist, R.E.; Gilmore, M.S. Contribution of the PAD1-Encoded Cytolysin to the Severity of Experimental Enterococcus faecalis Endophthalmitis. Infect. Immun. 1992, 60, 2445-2452.

222. Engelbert, M.; Mylonakis, E.; Ausubel, F.M.; Calderwood, S.B.; Gilmore, M.S. Contribution of Gelatinase, Serine Protease, and Fsr to the Pathogenesis of Enterococcus faecalis Endophthalmitis. Infect. Immun. 2004, 72, 3628-3633. [CrossRef] [PubMed]

223. Mylonakis, E.; Engelbert, M.; Qin, X.; Sifri, C.D.; Murray, B.E.; Ausubel, F.M.; Gilmore, M.S.; Calderwood, S.B. The Enterococcus faecalis FsrB Gene, a Key Component of the Fsr Quorum-Sensing System, Is Associated with Virulence in the Rabbit Endophthalmitis Model. Infect. Immun. 2002, 70, 4678-4681. [CrossRef]

224. Suzuki, T.; Wada, T.; Kozai, S.; Ike, Y.; Gilmore, M.S.; Ohashi, Y. Contribution of Secreted Proteases to the Pathogenesis of Postoperative Enterococcus faecalis Endophthalmitis. J. Cataract Refract. Surg. 2008, 34, 1776-1784. [CrossRef]

225. LaGrow, A.L.; Coburn, P.S.; Miller, F.C.; Land, C.; Parkunan, S.M.; Luk, B.T.; Gao, W.; Zhang, L.; Callegan, M.C. A Novel Biomimetic Nanosponge Protects the Retina from the Enterococcus faecalis Cytolysin. mSphere 2017, 2, e00335-17. [CrossRef]

226. Coburn, P.S.; Miller, F.C.; LaGrow, A.L.; Land, C.; Mursalin, M.H.; Livingston, E.; Amayem, O.; Chen, Y.; Gao, W.; Zhang, L.; et al. Disarming Pore-Forming Toxins with Biomimetic Nanosponges in Intraocular Infections. mSphere 2019, 4, e00262-19. [CrossRef]

227. Jackson, T.L.; Eykyn, S.J.; Graham, E.M.; Stanford, M.R. Endogenous Bacterial Endophthalmitis: A 17-Year Prospective Series and Review of 267 Reported Cases. Surv. Ophthalmol. 2003, 48, 403-423. [CrossRef]

228. Jackson, T.L.; Paraskevopoulos, T.; Georgalas, I. Systematic Review of 342 Cases of Endogenous Bacterial Endophthalmitis. Surv. Ophthalmol. 2014, 59, 627-635. [CrossRef] [PubMed]

229. Podschun, R.; Ullmann, U. Klebsiella Spp. as Nosocomial Pathogens: Epidemiology, Taxonomy, Typing Methods, and Pathogenicity Factors. Clin. Microbiol. Rev. 1998, 11, 589-603. [CrossRef] [PubMed]

230. Yu, W.-L.; Ko, W.-C.; Cheng, K.-C.; Lee, H.-C.; Ke, D.-S.; Lee, C.-C.; Fung, C.-P.; Chuang, Y.-C. Association between RmpA and MagA Genes and Clinical Syndromes Caused by Klebsiella pneumoniae in Taiwan. Clin. Infect. Dis. 2006, 42, 1351-1358. [CrossRef] [PubMed]

231. Fang, C.-T.; Chuang, Y.-P.; Shun, C.-T.; Chang, S.-C.; Wang, J.-T. A Novel Virulence Gene in Klebsiella pneumoniae Strains Causing Primary Liver Abscess and Septic Metastatic Complications. J. Exp. Med. 2004, 199, 697-705. [CrossRef] [PubMed] 
232. Chiu, C.-T.; Lin, D.-Y.; Liaw, Y.-F. Metastatic Septic Endophthalmitis in Pyogenic Liver Abscess. J. Clin. Gastroenterol. 1988, 10, 524-527. [CrossRef]

233. Cheng, D.L.; Liu, Y.C.; Yen, M.Y.; Liu, C.Y.; Wang, R.S. Septic Metastatic Lesions of Pyogenic Liver Abscess. Their Association with Klebsiella pneumoniae Bacteremia in Diabetic Patients. Arch. Intern. Med. 1991, 151, 1557-1559. [CrossRef]

234. Struve, C.; Bojer, M.; Nielsen, E.M.; Hansen, D.S.; Krogfelt, K.A. Investigation of the Putative Virulence Gene MagA in a Worldwide Collection of 495 Klebsiella Isolates: MagA Is Restricted to the Gene Cluster of Klebsiella pneumoniae Capsule Serotype K1. J. Med. Microbiol. 2005, 54, 1111-1113. [CrossRef]

235. Fang, F.C.; Sandler, N.; Libby, S.J. Liver Abscess Caused by MagA+ Klebsiella pneumoniae in North America. J. Clin. Microbiol. 2005, 43, 991-992. [CrossRef]

236. Fung, C.-P.; Chang, F.-Y.; Lee, S.-C.; Hu, B.-S.; Kuo, B.I.-T.; Liu, C.-Y.; Ho, M.; Siu, L.K. A Global Emerging Disease of Klebsiella pneumoniae Liver Abscess: Is Serotype K1 an Important Factor for Complicated Endophthalmitis? Gut 2002, 50, 420-424. [CrossRef]

237. Chee, S.P.; Ang, C.L. Endogenous Klebsiella Endophthalmitis-A Case Series. Ann. Acad. Med. Singap. 1995, 24, 473-478. [PubMed]

238. Ang, L.P.-K.; Lee, H.-M.; Eong, K.-G.A.; Yap, E.-Y.; Lim, A.T.-H. Endogenous Klebsiella Endophthalmitis. Eye 2000, 14, 855-860. [CrossRef] [PubMed]

239. Astley, R.A.; Coburn, P.S.; Madhumathi Parkunan, S.; Callegan, M.C. Modeling Intraocular Bacterial Infections. Prog. Retin. Eye Res. 2016, 54, 30-48. [CrossRef] [PubMed]

240. Wiskur, B.J.; Hunt, J.J.; Callegan, M.C. Hypermucoviscosity as a Virulence Factor in Experimental Klebsiella pneumoniae Endophthalmitis. Investig. Ophthalmol. Vis. Sci. 2008, 49, 4931-4938. [CrossRef] [PubMed]

241. Hunt, J.J.; Wang, J.-T.; Callegan, M.C. Contribution of Mucoviscosity-Associated Gene A (MagA) to Virulence in Experimental Klebsiella pneumoniae Endophthalmitis. Investig. Ophthalmol. Vis. Sci. 2011, 6340, 233-243.

242. Hunt, J.J.; Astley, R.; Wheatley, N.; Wang, J.; Michelle, C. TLR4 Contributes to the Host Response to Klebsiella Intraocular Infection. Curr. Eye Res. 2015, 39, 790-802. [CrossRef]

243. Eifrig, C.W.; Scott, I.U.; Flynn, H.W.; Miller, D. Endophthalmitis Caused by Pseudomonas aeruginosa. Ophthalmology 2003, 110, 1714-1717. [CrossRef]

244. Pinna, A.; Usai, D.; Sechi, L.A.; Zanetti, S.; Jesudasan, N.C.A.; Thomas, P.A.; Kaliamurthy, J. An Outbreak of Post-Cataract Surgery Endophthalmitis Caused by Pseudomonas aeruginosa. Ophthalmology 2009, 116, 2321-2326. [CrossRef]

245. Chen, K.-J.; Sun, M.-H.; Lai, C.-C.; Wu, W.-C.; Chen, T.-L.; Kuo, Y.-H.; Chao, A.-N.; Hwang, Y.-S.; Chen, Y.-P.; Wang, N.-K.; et al. Endophthalmitis Caused by Pseudomonas aeruginosa in Taiwan. Retina 2011, 31, 1193-1198. [CrossRef]

(C) 2019 by the authors. Licensee MDPI, Basel, Switzerland. This article is an open access article distributed under the terms and conditions of the Creative Commons Attribution (CC BY) license (http://creativecommons.org/licenses/by/4.0/). 